\title{
Rocking damage-free steel column base with friction devices: design procedure and numerical evaluation
}

\author{
Fabio Freddi $^{1, *}$, Christoforos A. Dimopoulos ${ }^{1}$, and Theodore L. Karavasilis ${ }^{2}$ \\ ${ }^{I}$ School of Engineering, University of Warwick, Coventry CV4 7AL, U.K. \\ ${ }^{2}$ Faculty of Engineering and the Environment, University of Southampton, Southampton SO17 1BJ, U.K. \\ "Corresponding Author. Tel.: +44 (0)7752360204.E-mail address: F.Freddi@warwick.ac.uk
}

\begin{abstract}
Earthquake resilient steel frames, such as self-centering frames or frames with passive energy dissipation devices, have been extensively studied during the past decade but little attention has been paid to their column bases. The paper presents a rocking damage-free steel column base, which uses post-tensioned (PT) high strength steel bars to control rocking behavior and friction devices (FDs) to dissipate seismic energy. Contrary to conventional steel column bases, the rocking column base exhibits monotonic and cyclic moment-rotation behaviors that are easily described using simple analytical equations. Analytical equations are provided for different cases including structural limit states that involve yielding or loss of post-tensioning in the PT bars. A step-by-step design procedure is presented, which ensures damage-free behavior, self-centering capability, and adequate energy dissipation capacity for a predefined target rotation. A 3D nonlinear finite element (FE) model of the column base is developed in ABAQUS. The results of the FE simulations validate the accuracy of the moment-rotation analytical equations and demonstrate the efficiency of the design procedure. Moreover, a simplified model for the column base is developed in OpenSees. Comparisons among the OpenSees and ABAQUS models demonstrate the efficiency of the former and its adequacy to be used in nonlinear dynamic analysis. A prototype steel building is designed as a self-centering moment-resisting frame with conventional or rocking column bases. Nonlinear dynamic analyses show that the rocking column base fully protects the first story columns from yielding and eliminate the first story residual drift without any detrimental effect on peak interstory drifts. The study focuses on the $2 \mathrm{D}$ rocking motion, and thus, ignores 3D rocking effects such as biaxial bending deformations in the FDs. The FE models, the analytical equations, and the design procedure will be updated and validated to cover 3D rocking motion effects after forthcoming experimental tests on the column base.
\end{abstract}

KEY WORDS: Column base; Steel frames; Self-centering; Rocking; Seismic design; Resilience

\section{INTRODUCTION}

Conventional seismic-resistant structures, such as steel moment resisting frames (MRFs), are designed to experience significant inelastic deformations under strong earthquakes $[1,2]$. Inelastic deformations result in damage of structural members and residual interstory drifts, which lead to high repair costs and disruption of the building use or occupation. The aforementioned socio-economic risks highlight the need for widespread implementation of minimal-damage structures, which can reduce both repair costs and downtime. Examples of such structures include steel frames equipped with self-centering beam-column connections, structural fuses, passive energy dissipation devices, self-centering braces, and others [3-7 and references therein]. These earthquake-resilient steel frame typologies have been extensively studied during the last decade but little attention has been paid to the behavior of their column bases.

Conventional steel column bases typically consist of an exposed steel base plate supported on grout and secured to the concrete foundation using steel anchor rods. In terms of their strength, column bases are typically designed as full-strength so that plastic hinges are developed in the bottom end of the first story columns $[1,8]$. Apart from the fact that plastic hinges in the columns induce non-repairable damage, this design approach needs very strong column bases with adequate over-strength to account for material variability [9]. Moreover, it results in conservative foundation designs since the full moment resistance of the column profile is transferred to the foundation. Alternatively, Eurocode 8 allows the design of partial-strength column bases, which are designed to develop plastic deformations $[1,8]$. Such design philosophy however needs the knowledge of the plastic rotation capacity of the column base under cyclic loading, which is difficult to predict [10]. A recent work developed a model for exposed steel column bases under cyclic loading and highlighted the complexity of their hysteretic behavior [11]. Most importantly, field observations after strong earthquakes confirmed the susceptibility of column bases to difficult-torepair damage such as concrete crushing, weld fracture, anchor rod fracture and base plate yielding [12]. In terms of their rotational stiffness, previous studies indicate that when designed as rigid, conventional column bases may be flexible under applied moments, while when designed as pinned, they do possess some rigidity. Under seismic loading, modelling the column bases of a steel MRF as rigid leads to unconservative results in terms of the first story drift and collapse resistance [13]. On the other hand, ignoring their rigidity and modelling the column bases as pinned could result in an over-conservative design of the columns. Therefore, the current design assumption of 
perfectly rigid or pinned column bases may produce erroneous results and jeopardize economy, serviceability and safety. In addition, the design of semi-rigid column bases is not straightforward as previous studies show that their rotational stiffness is strongly affected by the base plate flexibility and the magnitude and proportionality of the axial force [14].

Few research works proposed alternative column bases with the goal of overcoming the shortcomings of conventional column bases. Mackinven et al. [15] proposed a steel column base that involves the use of unbounded steel bars to act as re-centering devices while the column rocks under lateral loads. This column base lacks energy dissipation and develops significant stress concentration during rocking. Based on the concept of the sliding hinge originally developed by Clifton [16], MacRae et al. [17] proposed a steel column base where a pin is used to resist axial and shear forces. Flexural resistance and energy dissipation is provided by friction due to relative movement of the column flanges with respect to foundation flange plates with slotted holes. This column base has minimaldamage behavior in the strong column axis direction. Yamanishi et al. [18] developed a steel column base that involves exposed yield bolts anchored on a strong plate welded on the column and connected to the foundation anchor bolts through couplers. The yield bolts are the only components that experience damage and can be easily replaced. Chi and Liu [19] developed a damage-free steel column base that involves post-tensioned (PT) bars anchored at the mid-story height and at the bottom of a grade steel beam. Energy dissipation is provided by buckling-restrained steel plates, while shear resistance by bolted keeper plates. Chou and Chen [20] developed a similar self-centering column base but with PT bars anchored at the top and at the base of the first story columns. Recently, Borzouie et al. [21] presented experimental results on the behavior of a column base using an asymmetric friction connection. The system experiences rocking and energy is dissipated with friction/sliding surfaces parallel to the column strong axis. Superior behavior was achieved under loading in the column strong axis direction, while damage and stiffness degradation were observed under loading in the column weak axis direction.

This paper presents a rocking damage-free steel column base, which uses PT high strength steel bars to control rocking behavior and friction devices to dissipate seismic energy. The column base monotonic and cyclic momentrotation curves are defined with the aid of simple analytical equations that consider different limit states. In addition, a design procedure based on non-dimensional parameters and a simple graphical tool is presented. In order to validate the accuracy of the moment-rotation analytical equations and to demonstrate the efficiency of the design procedure, finite element (FE) simulations are performed in ABAQUS [22]. Moreover, a simplified twodimensional model of the rocking column base is developed in OpenSees [23]. The latter is used to conduct nonlinear dynamic analyses on self-centering moment-resisting frame (SC-MRFs) using the rocking column base.

\section{ROCKING DAMAGE-FREE COLUMN BASE}

\subsection{Structural details}

Figure 1 shows the proposed rocking damage-free column base, which in concept has similarities with the column base proposed by Kamperidis et al. [24]. A thick steel plate with rounded edges is welded on the bottom of a circular hollow steel section. The rounded edges help the column base to avoid stress concentration and damage during rocking of the hollow steel section on the steel base plate. Four PT high strength steel bars (or alternatively strands) are symmetrically placed around the center of the column base to increase the axial force and further control the rocking behavior. The PT bars are anchored to the bottom of the foundation (by running through steel ducts) and to a thick plate welded on the top of the hollow steel section (i.e. anchor plate in Figure 1(a)). Friction devices (FDs) are placed to the four sides of the column base to provide energy dissipation during rocking. As shown in Figure 2(a), the FDs consist of two external steel plates bolted to the base plate; an internal steel plate welded to the circular hollow section; and two plates of brass material in the interface. Rocking of the column base results in sliding of the internal plate with respect to the brass and external plates, and thus, in energy dissipation due to friction. The internal plate is drilled with inclined slotted holes to enable sliding, while the external plates and the brass plates are drilled with aligned rounded holes to accommodate four pre-tensioned bolts that are used to tune the friction force in the FDs. The dimensions of the inclined slotted holes are chosen to accommodate the superposition of all possible bolt travel paths during rocking of the column base as shown in Figure 2(a) [25]. As shown in Figure 2(b), a shear key is used to provide shear resistance to the column base. The shape of the shear key is designed with the goal of avoiding interlocking during rocking of the column base. Shear resistance is also provided by friction in the base plate-circular steel section interface. 

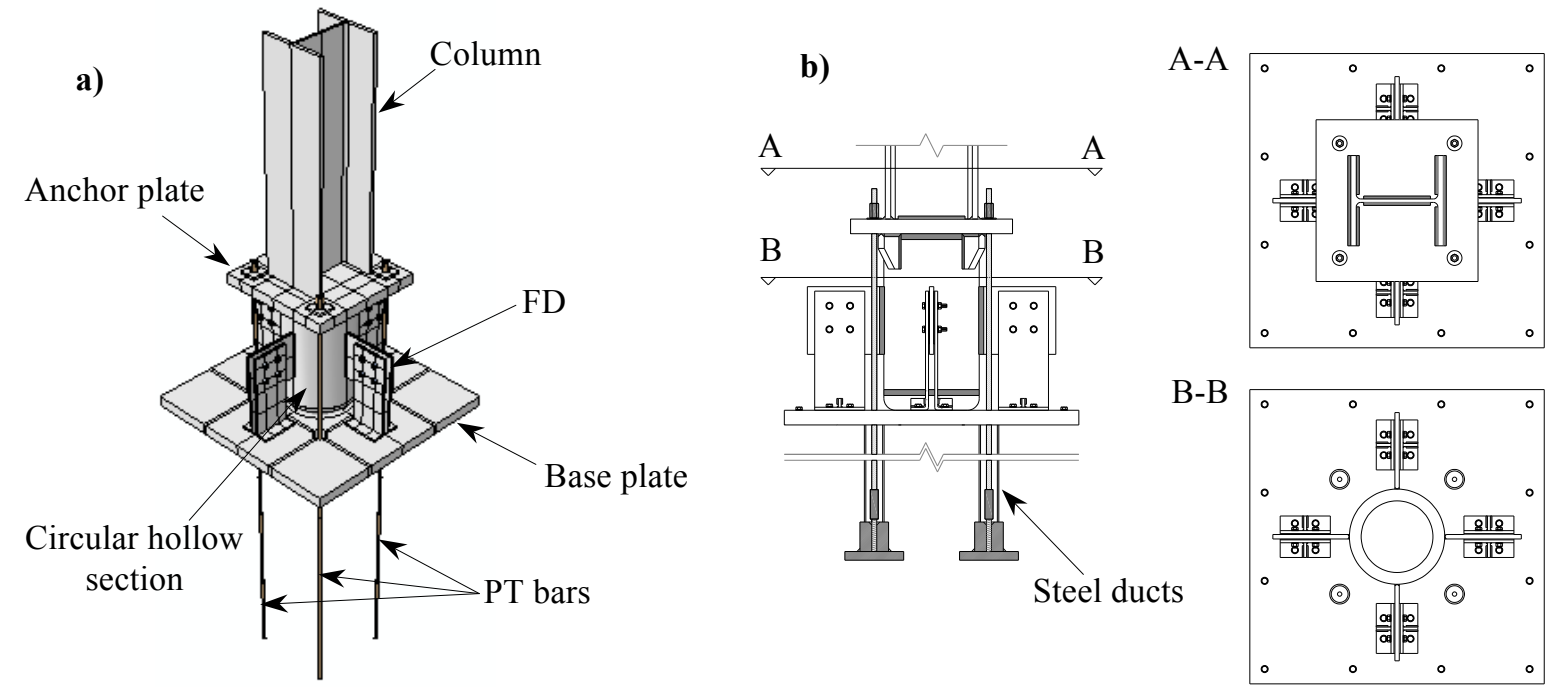

Figure 1. Proposed column base (a) 3D view; (b) lateral view and sections.
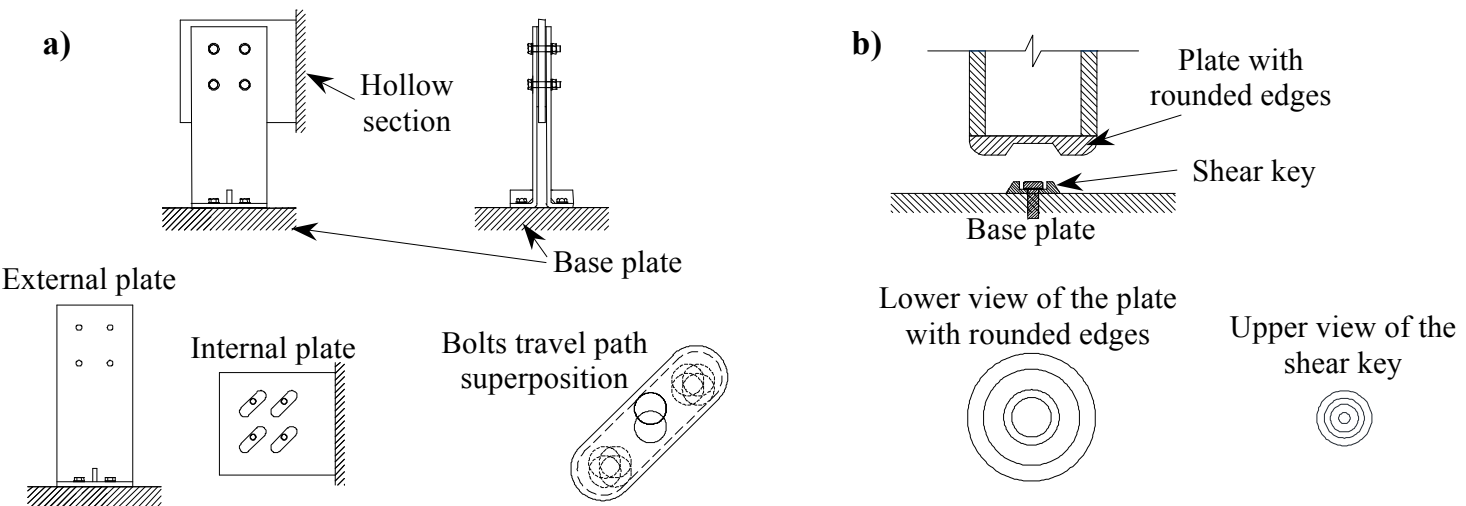

Figure 2. (a) Details of the friction device; (b) steel plate with rounded edges and shear key.

\subsection{Moment-rotation behavior}

Figure 3(a) shows the fundamental dimensions of the column base that control the moment-rotation behavior in the rocking direction, i.e. $b$ is the dimension of the contact surface; $b_{P T}$ is the distance among the PT bars; $b_{F D}$ is the distance among the centers of the FDs; and $h_{F D}$ is the distance of the centers of the FDs from the base plate. Figure 3 (b) shows the column base at the onset of rocking with respect to its right edge under the effect of the internal axial force $(N)$, shear force $(V)$, and bending moment $(M)$. In Figure 3(b), $F_{P T, u}$ and $F_{P T, d}$ are the forces in the PT bars, while $F_{F D, u}, F_{F D, d}$ and $F_{F D, c}$ are the forces in the FDs. The subscripts $u$ and $d$ denote whether the point of application of these forces will move upwards or downwards during rocking. The subscript $c$ denotes the force in each of the two central FDs. The lever arms of the forces in the PT bars with respect to the center of rotation are given by:

$$
z_{P T, u}=\frac{b_{P T}+b}{2} \quad z_{P T, d}=\frac{b_{P T}-b}{2}
$$

while the lever arms of the forces in the FDs are given by:

$$
z_{F D, u}=\sqrt{\left(\frac{b_{F D}+b}{2}\right)^{2}+h_{F D}^{2}} \quad z_{F D, c}=\frac{b}{2} \quad z_{F D, d}=\sqrt{\left(\frac{b_{F D}-b}{2}\right)^{2}+h_{F D}^{2}}
$$

The level arm of the central FDs is assumed equal to their horizontal distance from the center of rotation according to Equation 2. Further discussion on this assumption, which is true for rotations within the range of practical applications, is provided in Section 4. 

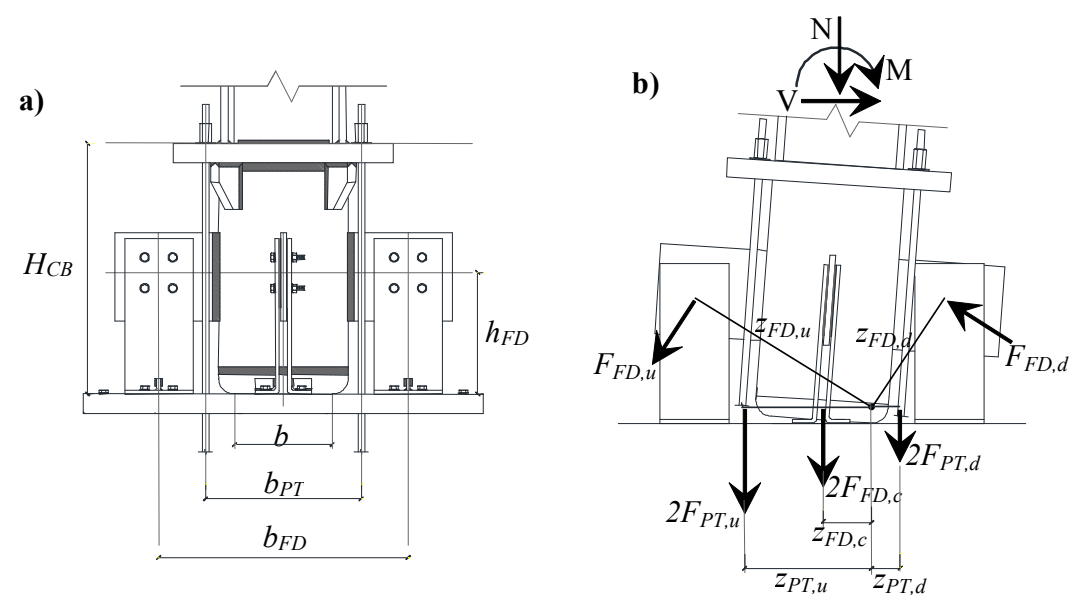

Figure 3. Column base (a) fundamental dimensions, (b) forces and lever arms of the FDs and PT bars during rocking for loading from left to right.

The moment contribution of the axial force, $N$, is given by:

$$
M_{N}=N \cdot \frac{b}{2}
$$

The forces in each PT bar are function of the rotation, $\theta$, of the column base and are given by:

$$
\begin{array}{ll}
F_{P T, u}=T_{P T}+K_{P T} \cdot z_{P T, u} \cdot \theta & \text { for } \quad \theta \leq \theta_{P T, u, y} \\
F_{P T, d}=T_{P T}-K_{P T} \cdot z_{P T, d} \cdot \theta & \text { for } \quad \theta \leq \theta_{P T, d, f}
\end{array}
$$

where $T_{P T}$ is the initial post-tensioning force of each PT bar; $K_{P T}=E_{P T} A_{P T} / L_{P T}$ is the stiffness of each PT bar; $E_{P T}$, $A_{P T}$ and $L_{P T}$ are respectively the Young's modulus, the cross-sectional area and the length of each PT bar; $\theta_{P T, u, y}$ is the rotation at which the PT bars (in position $u$ ) yield; and $\theta_{P T, d, f}$ is the rotation at which the force of the PT bars (in position $d$ ) becomes zero, i.e. when loss of post-tensioning occurs. The PT bars should be designed to avoid either yielding or loss of post-tensioning for a target rotation $\theta_{T}$ by using the following inequalities:

$$
\begin{gathered}
\theta_{P T, u, y}=\frac{F_{P T, y}-T_{P T}}{K_{P T} \cdot z_{P T, u}} \quad \rightarrow \quad L_{P T} \geq \frac{E_{P T} \cdot A_{P T} \cdot z_{P T, u} \cdot \theta_{T}}{F_{P T, y}-T_{P T}} \\
\theta_{P T, d, f}=\frac{T_{P T}}{K_{P T} \cdot z_{P T, d}} \quad \rightarrow \quad T_{P T} \geq K_{P T} \cdot z_{P T, d} \cdot \theta_{T}
\end{gathered}
$$

where $F_{P T, y}=f_{y, P T} \cdot A_{P T}$ is the yield force of the PT bars and $f_{y, P T}$ is the yield stress of their steel material. Therefore, the moment contribution of the PT bars is given by:

$$
M_{P T}(\theta)=2\left[T_{P T}\left(z_{P T, u}-z_{P T, d}\right)+K_{P T}\left(z_{P T, u}^{2}+z_{P T, d}^{2}\right) \theta\right] \quad \text { for } \theta \leq \theta_{T}
$$

The friction force, $F_{F D, i}$, in each $\mathrm{FD}$ is given by:

$$
F_{F D, i}=\mu_{F D} \cdot n_{b} \cdot N_{b} \quad \text { with } i=u, c, d
$$

where $\mu_{F D}$ is the friction coefficient of the surfaces in contact; $n_{b}$ is the number of bolts and $N_{b}$ is the bolt preloading force. The bolts preloading force can be determined from the tightening torque by means of the following equation according to Latour et al. [26]:

$$
N_{b}=\frac{T_{b}}{0.2 d}
$$

where $T_{b}$ is the value of the tightening torque and $d$ is the bolt diameter. Therefore, the moment contribution of the FDs is given by:

$$
M_{F D}=2 \cdot F_{F D}\left(z_{F D, u}+2 \cdot z_{F D, c}+z_{F D, d}\right)
$$


Figure 4(a) shows the moment contributions of the axial force, $M_{N}$; of the PT bars, $M_{P T}$; and of the FDs, $M_{F D}$. The decompression moment, $M_{E}$, and the moment at the onset of rocking, $M_{D}$, are given by:

$$
\begin{gathered}
M_{E}=M_{N}+M_{P T, 0} \\
M_{D}=M_{E}+M_{F D}
\end{gathered}
$$

where $M_{P T, 0}$ is the moment provided by the PT bars at zero rotation (i.e. $\theta=0.0$ in Equation 6).

a)

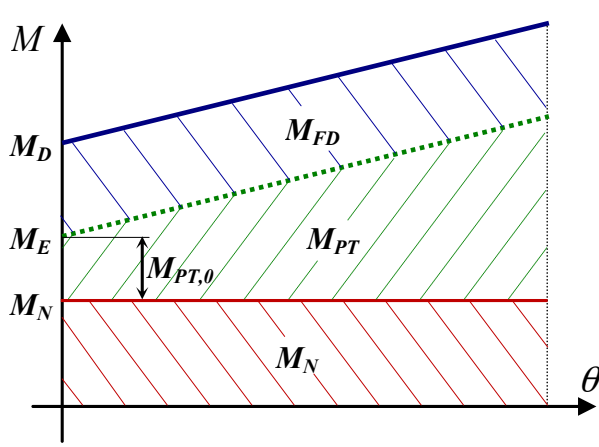

b)

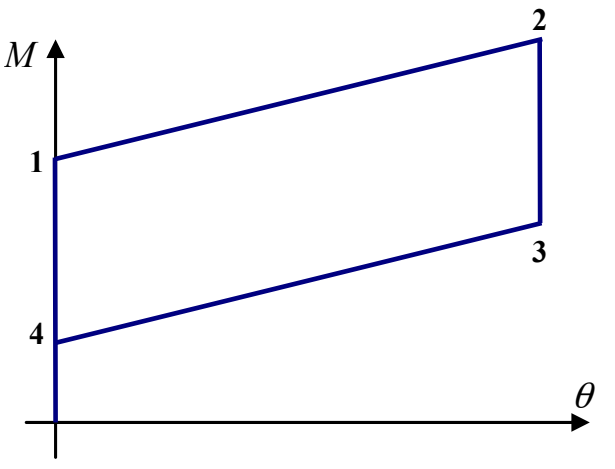

Figure 4. Moment-rotation behavior of the column base. (a) Moment contribution of the axial force, $M_{N}$; of the PT bars, $M_{P T}$; and of the FDs, $M_{F D}$; (b) hysteretic behavior.

The rotational stiffness contribution of the PT bars is given by:

$$
S_{P T}=2 K_{P T}\left(z_{P T, u}^{2}+z_{P T, d}^{2}\right)
$$

and therefore, the moments corresponding to points 1 to 4 of the cyclic $M-\theta$ behavior of the column base in Figure 4(b) are given by:

$$
\begin{gathered}
M_{1}=M_{D}=M_{N}+M_{P T, 0}+M_{F D} \\
M_{2}=M_{D}+S_{P T} \theta_{2} \\
M_{3}=M_{D}+S_{P T} \theta_{2}-2 M_{F D} \\
M_{4}=M_{D}-2 M_{F D}
\end{gathered}
$$

From $M_{2}$ to $M_{3}$ there is a sudden moment reduction equal to $2 M_{F D}$ for a constant rotation value due to the rigid behavior of the FDs and the change in column base rotation direction.

To ensure that the column base provides full self-centering capability, the following relation should be satisfied:

$$
M_{4} \geq 0 \quad \rightarrow \quad M_{E} \geq M_{F D}
$$

The aforementioned equations do not account for geometrical nonlinearities (i.e. P- $\Delta$ effects), material nonlinearities (i.e. PT bar yielding), and mechanical nonlinearities (i.e. loss of post-tensioning in the PT bars). Analytical equations for the definition of the monotonic moment-rotation behavior of the column base accounting for such nonlinearities are provided in the Appendix.

\section{DESIGN PROCEDURE FOR THE ROCKING COLUMN BASE}

This section describes the steps of a design procedure that ensures that the column base has damage-free behavior, self-centering capability, and adequate energy dissipation capacity. The design procedure requires as input the crosssection of the column; the axial force in the column due to the gravity loads of the seismic load combination, $N_{E d, G}$; the axial force due to the seismic load combination, $N_{E d}$; and the first story drift due to the seismic load combination.

\subsection{Geometry of the column base}

Based on the cross-section of the first story column, the fundamental dimensions of the column base $\left(i . e . b_{,} b_{P T}, b_{F D}\right.$, and $h_{F D}$ ) are selected with respect to practical and geometric considerations. The PT bars should be as close as possible to the column to avoid large elongations and yielding during rocking as well as to decrease the moments that they induce on the anchor plate. Given the fundamental dimensions of the column base, the parameters $z_{P T, u}$, $z_{P T, d}, z_{F D, u}, z_{F D, c}$ and $z_{F D, d}$ can be calculated by using Equations 1 and 2. 


\subsection{Design of the PT bars}

The moment at the target rotation, $M_{T}$, should be lower than the plastic moment of resistance of the column, $M_{N, R d}$ [27], to protect the latter from yielding. Therefore, $M_{T}$ is defined as:

$$
M_{T}=\frac{M_{N, R d}}{\gamma_{T}}
$$

where $\gamma_{T}$ can be calculated as $1.1 \gamma_{o v}$ according to Eurocode 8 [1]. The material over-strength factor, $\gamma_{o v}$, reflects the ratio of the actual-to-design yield strength of steel, which, in the absence of measurements, can be assumed equal to1.25. $\gamma_{o v}$ is further amplified by 1.1 to account for other material effects such as strain hardening and strain rate. Therefore, the typical value of $\gamma_{T}$ is 1.375 but higher values could be used to achieve more conservative designs against column yielding. To ensure self-centering behavior, the moment provided by the FDs, $M_{F D}$, should not exceed the decompression moment, $M_{E}$ (see Eq. (10)), i.e.

$$
M_{F D}=\frac{M_{E}}{\alpha_{s c}}
$$

where $\alpha_{s c}$ is a design parameter with a value larger than unity. The self-centering behavior of the column base could be influenced by several aspects, i.e. hardening of the friction material, etc. Recommendations for the choice of appropriate values for the parameter $\alpha_{s c}$ is out of the scope of the present paper and will be a task after a near future experimental evaluation of the column base. The moment at the onset of rocking, $M_{D}$, can be calculated as:

$$
M_{D}=M_{E}+M_{F D}=\left(1+\frac{1}{\alpha_{s c}}\right) M_{E}=\left(1+\frac{1}{\alpha_{s c}}\right)\left[N_{E d, G} \frac{b}{2}+2 T_{P T}\left(z_{P T, u}-z_{P T, d}\right)\right]
$$

Then, the moment at the target rotation, $M_{T}$, can be calculated as:

$$
M_{T}=M_{D}+S_{P T} \theta_{T}=\left(1+\frac{1}{\alpha_{s c}}\right)\left[N_{E d, G} \frac{b}{2}+2 T_{P T}\left(z_{P T, u}-z_{P T, d}\right)\right]+2 K_{P T}\left(z_{P T, u}^{2}+z_{P T, d}^{2}\right) \theta_{T}
$$

By defining $\kappa=\sigma_{P T} / f_{y, P T}$ as the stress ratio in the PT bars ( $\sigma_{P T}$ as the stress in the PT bars), $M_{T}$ can be expressed as:

$$
M_{T}=\left(1+\frac{1}{\alpha_{s c}}\right)\left[N_{E d, G} \frac{b}{2}+2 \kappa A_{P T} f_{y, P T}\left(z_{P T, u}-z_{P T, d}\right)\right]+2 \frac{E_{P T} A_{P T}}{L_{P T}}\left(z_{P T, u}^{2}+z_{P T, d}^{2}\right) \theta_{T}
$$

Further re-arrangement of Equation 19 provides:

$$
\kappa=\frac{1}{2 A_{P T} f_{y, P T}\left(z_{P T, u}-z_{P T, d}\right)}\left[\frac{M_{T}-2 \frac{E_{P T} A_{P T}}{L_{P T}}\left(z_{P T, u}^{2}+z_{P T, d}^{2}\right) \theta_{T}}{1+\frac{1}{\alpha_{s c}}}-N_{E d, G} \frac{b}{2}\right]
$$

Equation 20 shows that $\kappa, A_{P T}$ and $L_{P T}$ are the design variables, while all the other parameters are selected by the designer. A simple re-arrangement of Equations 5 yields:

$$
\begin{gathered}
\kappa \leq 1-\frac{E_{P T} \cdot z_{P T, u} \cdot \theta_{T}}{f_{y, P T} \cdot L_{P T}}=\kappa_{\text {max }} \\
\kappa \geq \frac{E_{P T} \cdot z_{P T, d} \cdot \theta_{T}}{f_{y, P T} \cdot L_{P T}}=\kappa_{\text {min }}
\end{gathered}
$$

Equation 20 together with Equations 21 can be used to calculate the design variables $\kappa, A_{P T}$ and $L_{P T}$.

\subsection{Design of the FDs}

Once the PT bars are designed, Equation 16 is used to calculate the $M_{F D}$. Then, the FDs can be designed by selecting appropriate values of the parameters in Equation 9.

\subsection{Design example}

The novel column base is designed for a HEB 300 column cross-section; axial force $N_{E d, G}$ equal to $537.8 \mathrm{kN}$; and axial force $N_{E d}$ equal to $565.3 \mathrm{kN}$. The plastic moment of resistance $M_{N, R d}$ is calculated equal to $308.9 \mathrm{kNm}$. The target rotation is assumed equal to $0.023 \mathrm{rads}$. Based on the geometry of the column cross-section, a circular hollow section with $323.9 \mathrm{~mm}$ diameter and $40 \mathrm{~mm}$ thickness is adopted. A circular steel plate with the same diameter is 
welded at the bottom of the hollow section. Standard mechanical processing provides this plate with rounded circular edges having a radius of $40 \mathrm{~mm}$ as well as with appropriate space to accommodate the shear key. The contact surface has a dimension $b$ equal to $243.9 \mathrm{~mm}$. The anchor plate of the PT bars in the top of the hollow steel section is square and has width and thickness equal to $550 \mathrm{~mm}$ and $50 \mathrm{~mm}$, respectively. The distance among the PT bars $b_{P T}$ is selected equal to $390.0 \mathrm{~mm}$. Moreover, Table 1 provides the assumed material properties (E: Young's modulus; $f_{y}$ : yield stress; $f_{u}$ : ultimate stress; and $\beta$ : strain hardening ratio), which has been selected on the basis of experimental results $[28,29]$.

Table 1. Material properties.

\begin{tabular}{c|c|ccccc} 
Elements & & $\boldsymbol{E}$ & $\boldsymbol{f}_{\boldsymbol{y}}$ & $\boldsymbol{f}_{\boldsymbol{u}}$ & $\boldsymbol{\beta}$ & $\boldsymbol{v}$ \\
\hline & & {$[\mathrm{GPa}]$} & {$[\mathrm{MPa}]$} & {$[\mathrm{MPa}]$} & {[]} & {[]} \\
\hline Column and plates & $\mathrm{S} 355$ & 210 & 355 & 510 & 0.00338 & 0.30 \\
PT bars & $* * *$ & 205 & 900 & 1100 & 0.01754 & 0.30 \\
Bolts & Class 10.9 & 210 & 900 & 1000 & 0.00855 & 0.30 \\
Brass & $* * *$ & 100 & $* * *$ & $* * *$ & $* * *$ & 0.35 \\
\hline
\end{tabular}

Figure 5(a) shows the variation of $\kappa$ with respect to $L_{P T}$ for different $d_{P T}$ values. The coefficients $\gamma_{T}$ and $\alpha_{s c}$ have been assumed equal to 1.4 and 1.3, respectively. Any pair of $\kappa$ and $L_{P T}$ with values within the highlighted acceptable zone can be selected. However, the optimum design that satisfies the design criteria and minimizes the length of the PT bars should be a point close to the intersection of the $\kappa_{\min }$ and $\kappa_{\max }$ curves. In this example, $d_{P T}$ is selected equal to $15 \mathrm{~mm}, L_{P T}$ equal to $2240 \mathrm{~mm}$, and $\kappa$ equal to 0.189 . The latter corresponds to $T_{P T}$ equal to $30.0 \mathrm{kN}$. The rotations $\theta_{P T, u, y}$ and $\theta_{P T, d, f}$ are equal to $0.0252 \mathrm{rads}$ and $0.0255 \mathrm{rads}$, respectively. Figure 5(b) shows the moment-rotation behavior for the column base. The decompression moment, $M_{E}$, the moment at the onset of rocking, $M_{D}$, and the moment provided by the FDs, $M_{F D}$, are equal to $80.3 \mathrm{kNm}, 142.0 \mathrm{kNm}$ and $61.7 \mathrm{kNm}$, respectively.
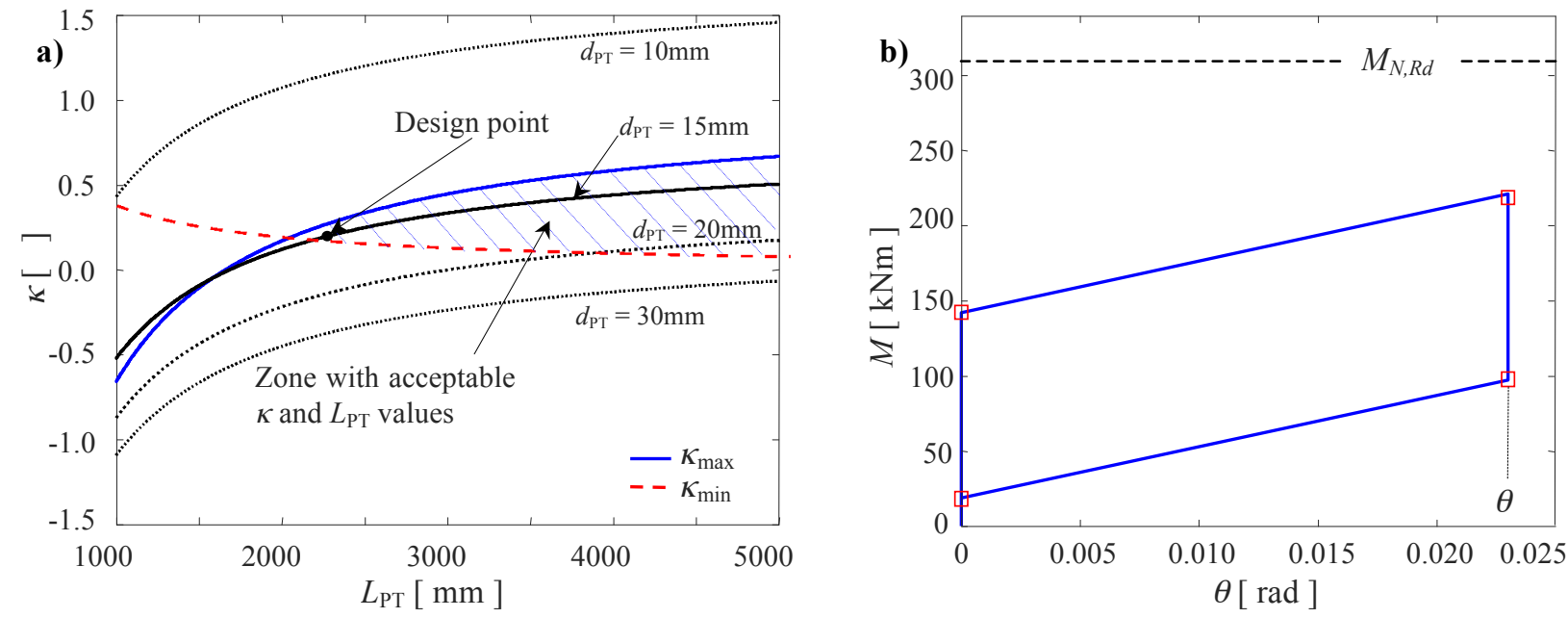

Figure 5. (a) Variation of $\kappa$ with respect to $L_{P T}$ for different $d_{P T}$ values; (b) moment-rotation behavior of the column base.

FDs are introduced on the four sides of the column base as described in Section 2; the relevant dimensions are $b_{F D}=623.9 \mathrm{~mm}$ and $h_{F D}=315 \mathrm{~mm}$. The thickness of the internal and external plates of the FDs are $15 \mathrm{~mm}$ and $10 \mathrm{~mm}$, respectively. Two $3 \mathrm{~mm}$ thick brass plates are used as friction interfaces. The friction coefficient at the brass-steel interface is assumed equal to 0.15 according to [26]. M12 class 10.9 bolts are preloaded at $45 \mathrm{kN}$ by tightening. The dimensions of the slotted holes are designed to allow a very large rotation (i.e. close to 0.06rads) without bearing of the bolts on the plates. Figure 6 summarizes the geometry of the column base. 

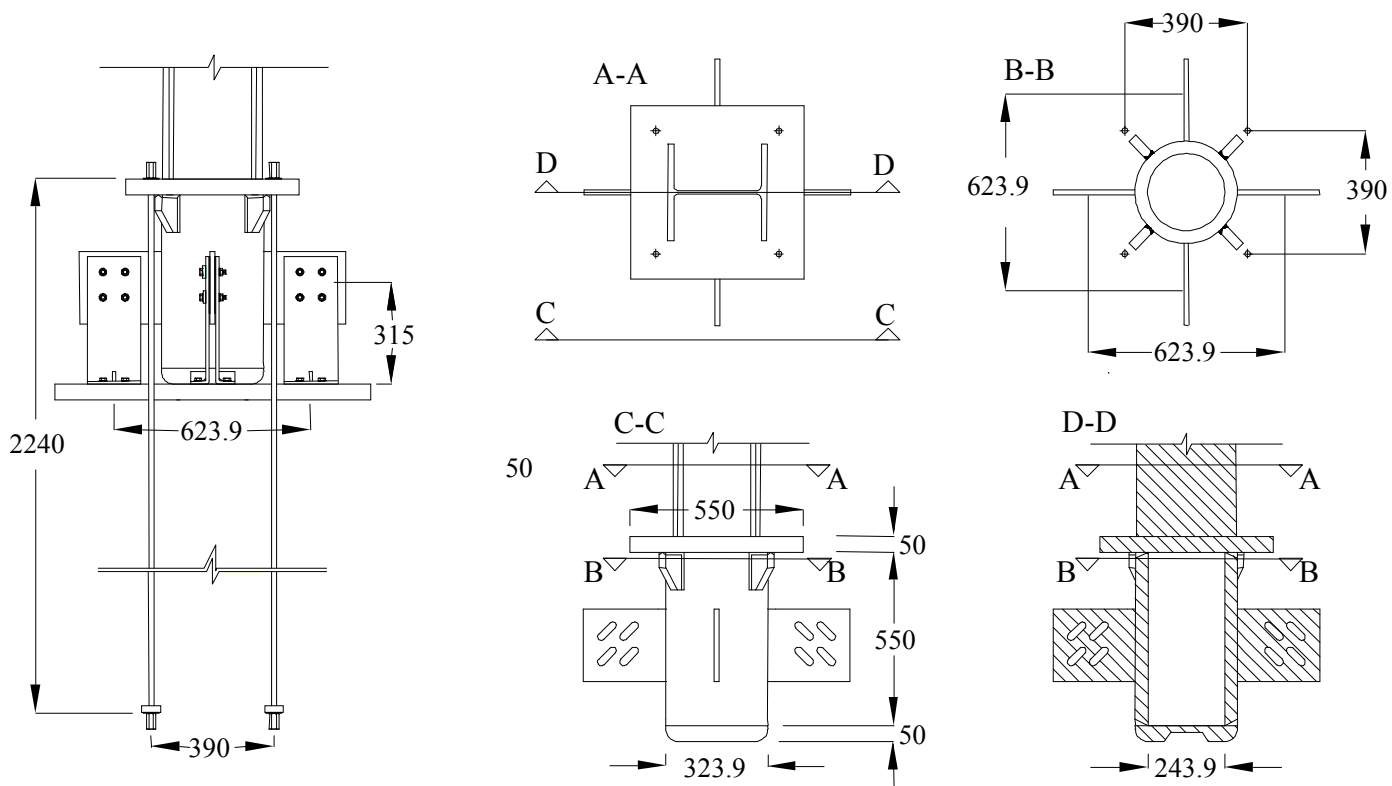

Figure 6. Geometry of the column-base (dimensions in $\mathrm{mm}$ ).

\section{NONLINEAR MODELS FOR THE COLUMN BASE}

A detailed three-dimensional nonlinear FE model in ABAQUS [22] and a simplified two-dimensional nonlinear model in OpenSees [23] are developed to simulate the cyclic behavior of the column base designed in the previous Section (see Figure (6)). The results of the two models are compared and used to assess the effectiveness of the analytical equations presented in Section 2.2 and the effectiveness of the design procedure presented in Section 3.

\subsection{FEM model in ABAQUS}

All the components of the column base are modeled using the eight-node linear brick element (C3D8R) available in the ABAQUS library. Elements C3D8R rely on 'reduced integration' and 'hourglass control' and meshing is carried out using the 'structured' and 'swift' mesh techniques. An overview of the model and details of the mesh in areas with contact interactions are shown in Figure 7.

a)

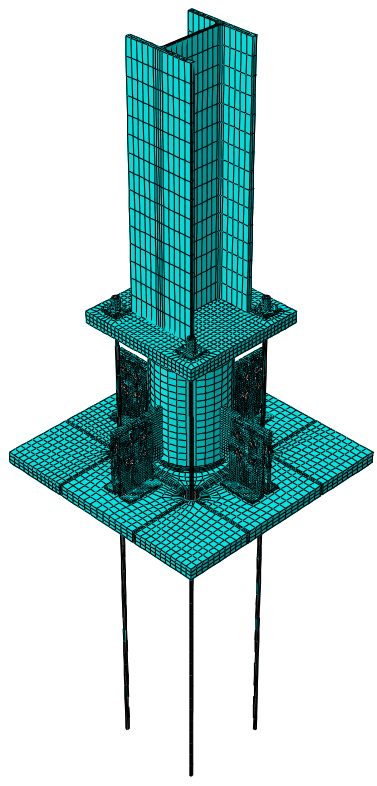

b)

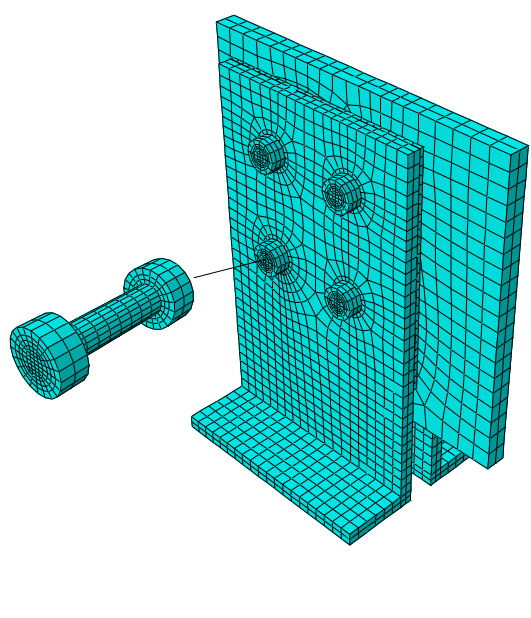

c)
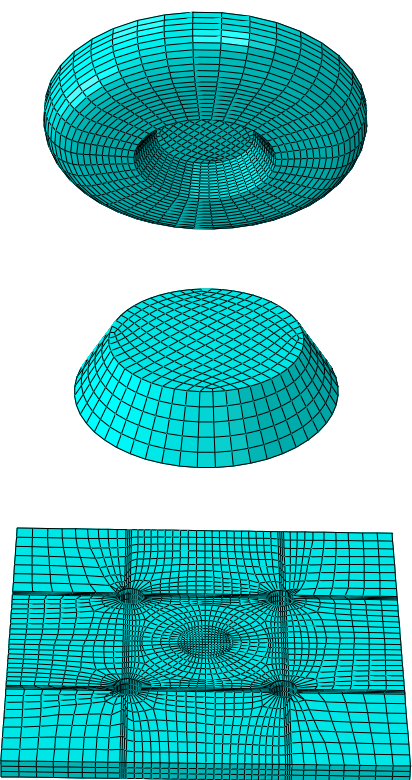

Figure 7. (a) Overview of the FE model of the column base, (b) FE model of the plates and bolts of the friction device, and (c) FE model for the plate with rounded edges, the shear key, and the base plate. 
The bottom surface of the base plate and the bottom ends of the PT bars are fully fixed. Lateral and gravity loads are simulated by a controlled horizontal displacement and a concentrated vertical force applied at the centroid of the cross-section at the top of the column. A multi-point constraint is used to uniformly distribute these actions to all nodes of the top column cross-section. A 'bolt load' is used to model the initial post-tensioning force in the PT bars and the bolts. The 'apply force' option is used to keep the force in the bolts constant throughout the analysis, while the 'adjust length' option is used to allow the force in the PT bars to change due to elongation or shortening during rocking.

A TIE constraint is used to simulate welding (i.e. monolithic connection) among different parts of the column base, i.e. among the external plates of the friction devices and the base plate; the central plates of the friction devices and the circular hollow section; the column and the anchor plate; the circular hollow section and the anchor plate; the circular hollow section and the bottom circular plate with rounded edges; and the shear key and the base plate.

Convergence of the analysis is highly influenced by the definition of adequate contact properties. Contact interaction is defined among: the base plate and the bottom column base part with the rounded edges; the PT bars, the washer, and the anchor plate; the friction interfaces in the friction devices. The 'surface-to-surface' interaction property is used to describe the contact behavior between the aforementioned parts. This is implemented using the HARD contact property to describe the behavior in the direction normal to the interface plane, while the PENALTY option is used for the tangential response with values of the friction coefficient equal to 0.30 for interfaces among steel parts and 0.15 for the brass-steel interfaces of the FDs. Both 'automatic stabilization' and 'contact controls' are employed to overcome convergence problems associated with the nonlinear nature of the contact regions.

The 'von Mises yield criterion' coupled with 'isotropic hardening' was used to describe plasticity. The actual material properties used in the model are those reported in Table 1. The nonlinear equilibrium equations are solved using the 'static general' analysis procedure. The standard 'Full Newton' solution technique is adopted together with an automatic incrementation scheme for the application of the loading.

\subsection{Model in OpenSees}

The OpenSees model is shown in Figure 8. 'Elastic beam-column' elements with very high flexural stiffness are used to model the almost rigid components of the column base, i.e. the interface where rocking takes place; the anchor plate and the internal plates of the FDs.

To capture rocking behavior, 'zero-length' contact spring elements associated with the 'elastic compression-no tension' material of OpenSees [23] are used to connect the nodes of the column base and the fixed nodes of the column base at the locations of the centers of rotation. The compression stiffness of the contact springs is assumed equal to 20 times the axial stiffness of the column following the modeling approach in [30]. Larger values of this stiffness were found to produce practically the same results but with higher computational cost.

PT bars are modeled using truss elements running parallel to the column center-line axis and connected to the rigid elements simulating the anchor plate. To simulate loss of post-tensioning, a 'zero-length' contact spring with an 'elastic compression-no tension' material is introduced between the PT bars and the anchor plate. The truss elements have a cross-section area equal to the area of two PT bars to simulate the four PT bars of the column base in a simple way. To account for post-tensioning, an initial strain equal to $F_{P T, i} /\left(A_{P T} E_{P T}\right)$ is first assigned to the truss element. Post-tensioning results in shortening of the circular hollow section, which in turn decreases the posttensioning force. To account for this decrease, the initial strain in the 'truss' element was increased to ensure that the

post-tensioning force in the PT bars will be equal to $F_{P T, i}$ after the hollow section shortening. The 'InitStrainMaterial' [23] along with the elastoplastic material 'Steel01' is used for the PT bars truss elements.

The FDs are modeled by using truss elements placed at appropriate locations in order to account for their true level arms. The two central FDs are modeled by assigning to the internal truss element an area that is twice the area of the external ones. A bilinear elastic-plastic material ('Steel 01' material in OpenSees [23]) with very high initial stiffness and very low post-elastic stiffness is assigned to these truss elements in order to model the FDs behavior. The yield stress assigned to the material model and the area of the truss elements are appropriately defined to represent the friction force in the FDs. 


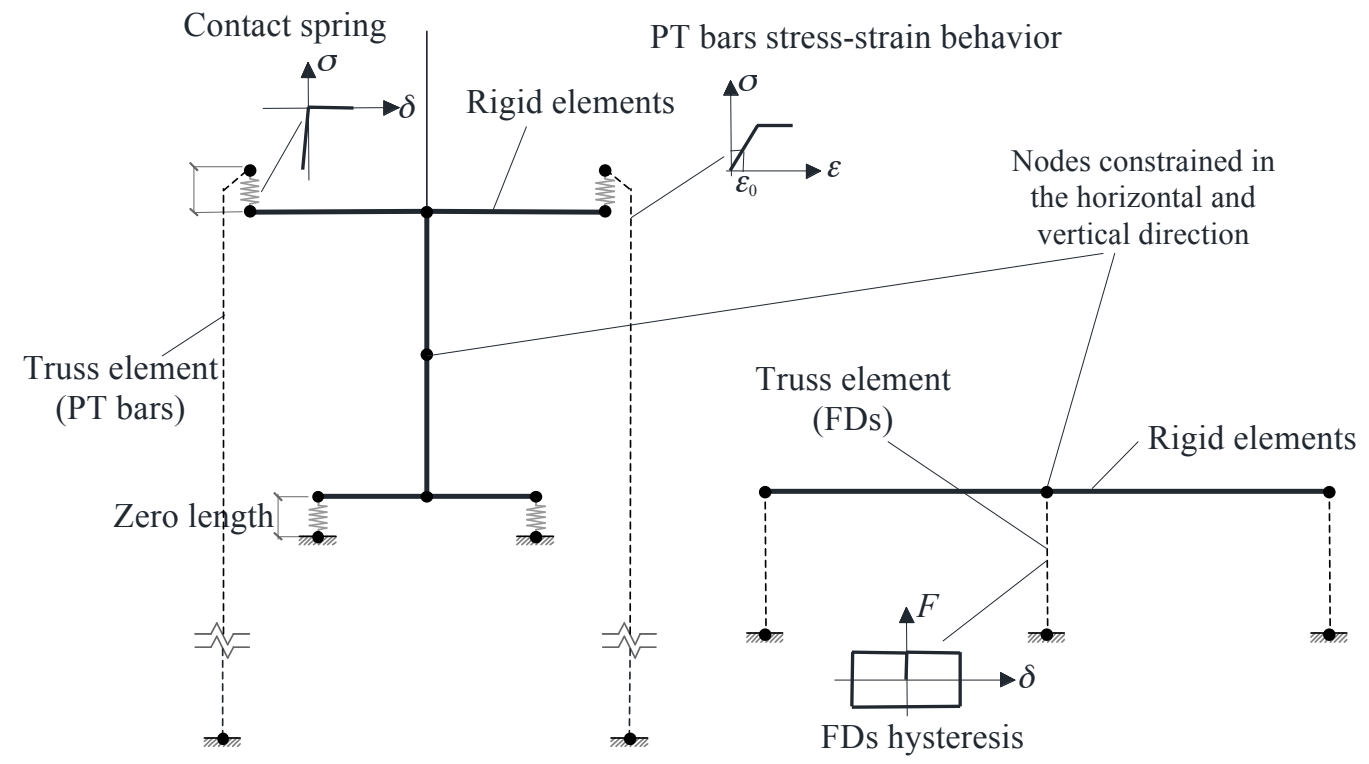

Figure 8. OpenSees model for the column base.

\subsection{Comparison of the results}

This Section compares the results from the ABAQUS FE model, the OpenSees model, and the analytical equations presented in Section 2.2. The results are plotted for cases with and without P- $\Delta$ effects, i.e. with or without including large displacement effects in the analyses. Figure 9(a) shows the monotonic moment-rotation curve of the column base for rotations up to $0.07 \mathrm{rads}$. The results show an excellent agreement for rotations of practical interest, i.e. up to 0.03 rads. For larger rotations, the analytical equations and the OpenSees model underestimate the moment compared to the ABAQUS model. Such underestimation is the result of the assumption (in the analytical equations and the OpenSees model) that the central FDs are rigid elements contributing to the moment of the column base solely through the vertical friction force. In reality though the plates of the central FDs develop deflections and internal bending moments under large column base rotations, which in turn increase the moment resisted by the column base. The latter explanation is supported by Figure 10(a) that shows full agreement among all results for the case of the same column base without central FDs. FDs using slender plates could limit the aforementioned increase in the moment resisted by the column base. Moreover, FDs could be equipped with hinges [31] to avoid bending deformations.

Both Figure 9(a) and Figure 10(a) show that the ABAQUS model predicts a sudden increase of the moment for rotation close to $0.06 \mathrm{rads}$. Such increase is due to the bearing of the bolts on the internal plate of the FDs as shown in Figure 10(b). The latter undesired behavior can be avoided by designing the slotted holes of the internal plate of the FDs for a longer bolt travel path.

Figure 9(b) shows the forces in the PT bars on the right and left sides of the column base (the loading has a direction from left to the right) as functions of the rotation of the column base. It is seen that yielding of the left PT bars and loss of post-tensioning of the right PT bars take place almost simultaneously at rotations close to the target one (i.e. 0.023rads) that was used to design the column base in Section 3.4. These results confirm the effectiveness of the proposed design procedure for the column base. After the target rotation, the force in the PT bars on the left slightly increase as consequence of the hardening of the material, while the force in the PT bars on the right remains equal to zero due to loss of post-tensioning. The results show a good agreement among the results from the OpenSees and the ABAQUS models. The ABAQUS model results show a slightly faster drop of the force in the PT bars on the right side due to the deformations in the circular hollow section and the plate with rounded edges. Numerical models in ABAQUS that consider these elements practically rigid show a perfect agreement with the results from OpenSees. 

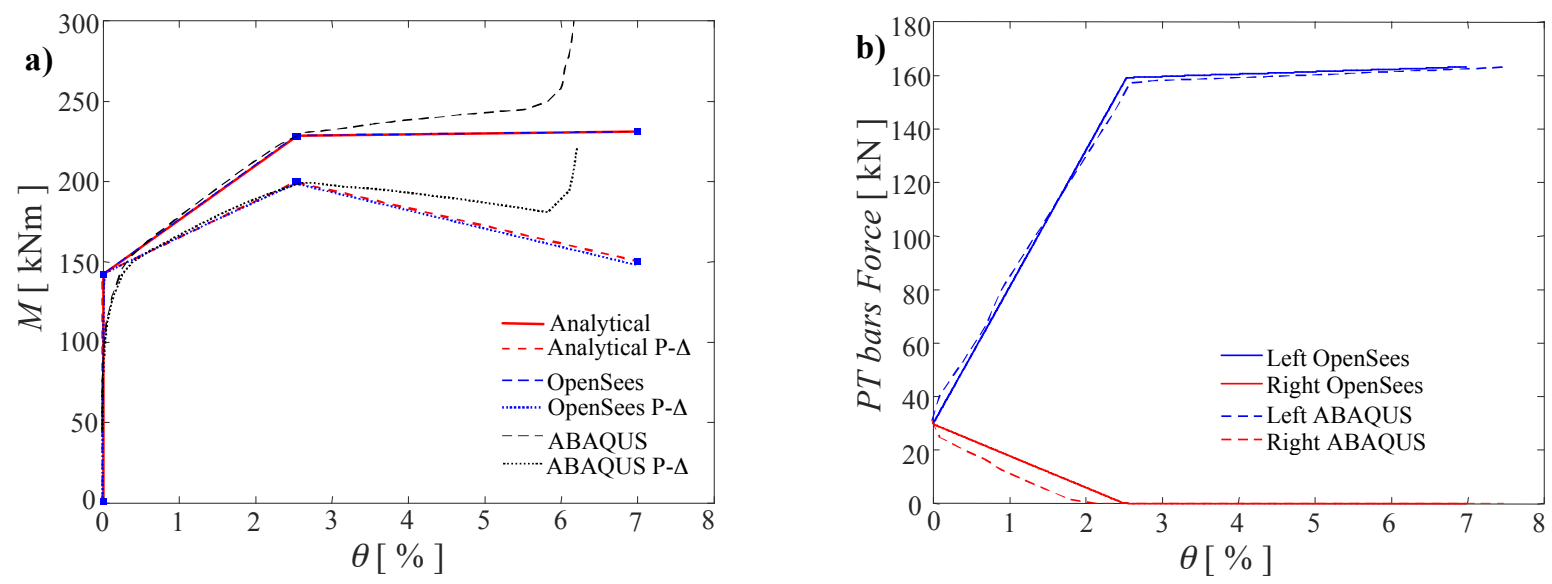

Figure 9. (a) Monotonic moment-rotation behavior of the column base; (b) forces in the PT bars for analysis with P$\Delta$ effects (results are practically the same for analysis without P- $\Delta$ effects).

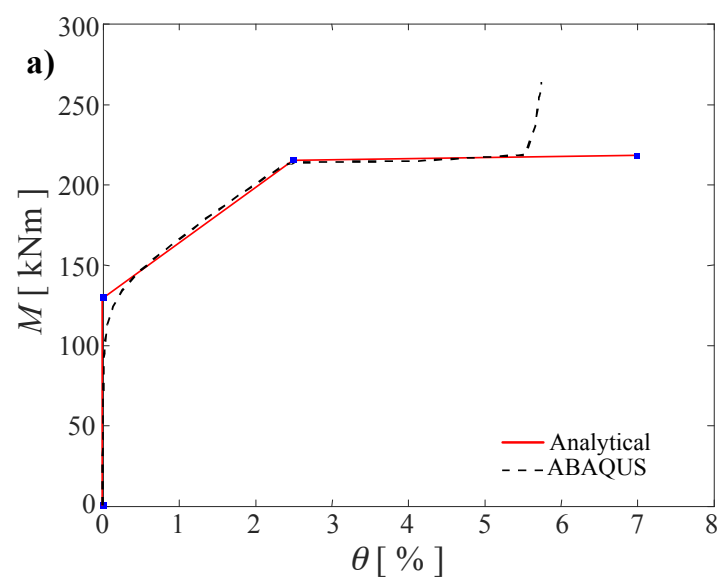

b)

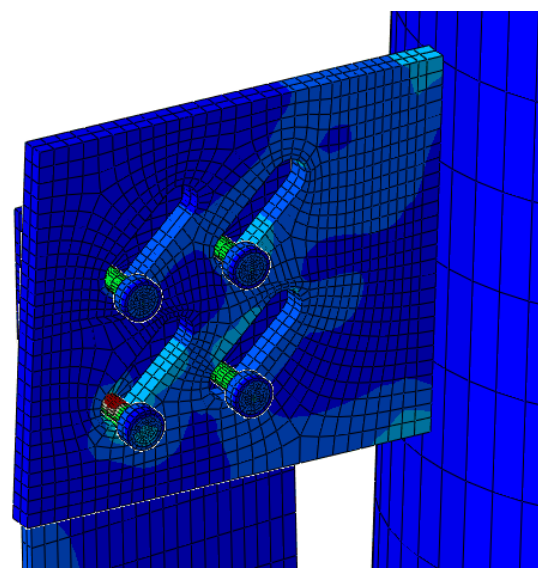

Figure 10. (a) Monotonic moment-rotation behavior of the column base without the central FDs; (b) bearing of bolts on the internal plate of the FDs.

Figure 11(a) shows the cyclic moment-rotation curve of the column base for rotations up to 0.02 rads. All the components of the column base remain elastic (i.e. damage-free). Moreover, the results from the analytical equations, the OpenSees model, and the ABAQUS model are in very good agreement. Smoother curves are obtained from ABAQUS due to modeling of the flexibility of all the column base components. Figure 11(b) shows the force in the PT bars for the same cyclic analysis, which again shows an excellent agreement among the OpenSees and ABAQUS models.

Figure 12 and Figure 13 show the cyclic hysteretic behavior of the column base for rotations up to 0.05 rads. In this case, comparison is performed only among the OpenSees and ABAQUS models since analytical equations are not derived for cyclic behavior that involves yielding of the PT bars. Figure 12(a) shows a very good agreement in the cyclic moment-rotation behaviors obtained from OpenSees and ABAQUS. Figure 12(b) shows the forces in the PT bars from the same cyclic analysis. In the first loading cycle, the PT bars on the left side of the column base yield and experience plastic elongation. Upon unloading, they reach a zero force for a positive rotation (point A in Figure 12(b)). The same behavior is experienced by the PT bars on the right side of the column base in the case of loading in the opposite direction.

Figure 13(a) shows the cyclic moment-rotation behavior of the column base under two cycles of loading corresponding to 0.04 and $0.05 \mathrm{rads}$. Results are presented from the OpenSees model and for the case of P- $\Delta$ effects. Figure 13(b) show the forces in the PT bars for the same analysis. Numbers in Figure 13(a) and (b) are used to correlate the results and highlight how yielding of the PT bars in the first loading cycle affect the moment-rotation behavior in the next loading cycle. 

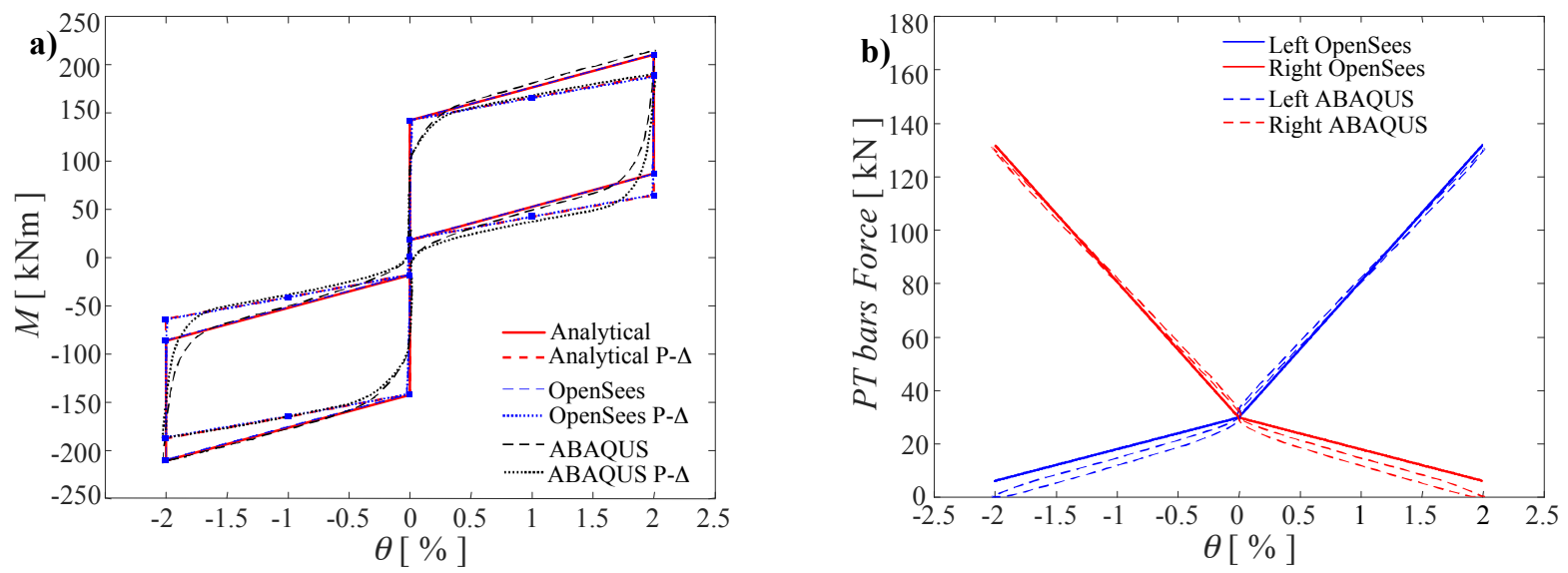

Figure 11. (a) Cyclic moment-rotation behavior of the column base for rotations up to 0.02rads; (b) Forces in the PT bars for analysis with P- $\Delta$ effects (results are practically the same for analysis without $\mathrm{P}-\Delta$ effects).
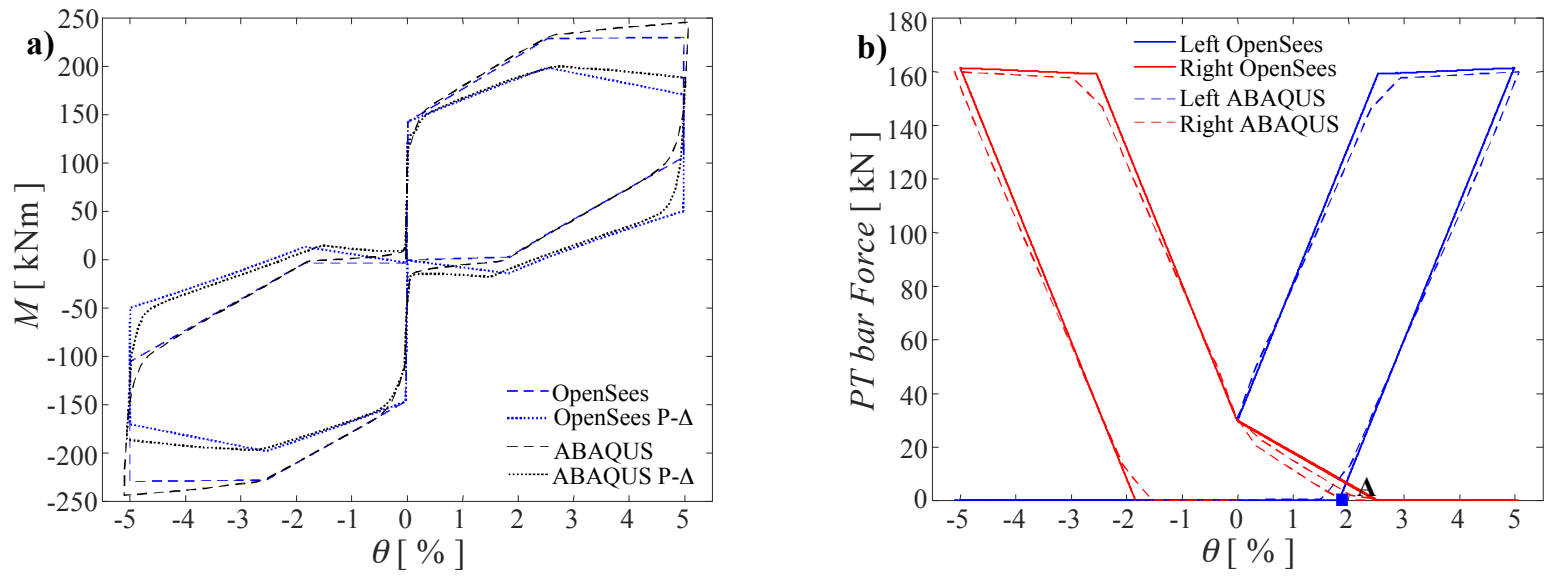

Figure 12. (a) Cyclic moment-rotation behavior of the column base for rotations up to 0.05 rads; (b) forces in the PT bars for analysis with P- $\Delta$ effects (results are practically the same for analysis without P- $\Delta$ effects)
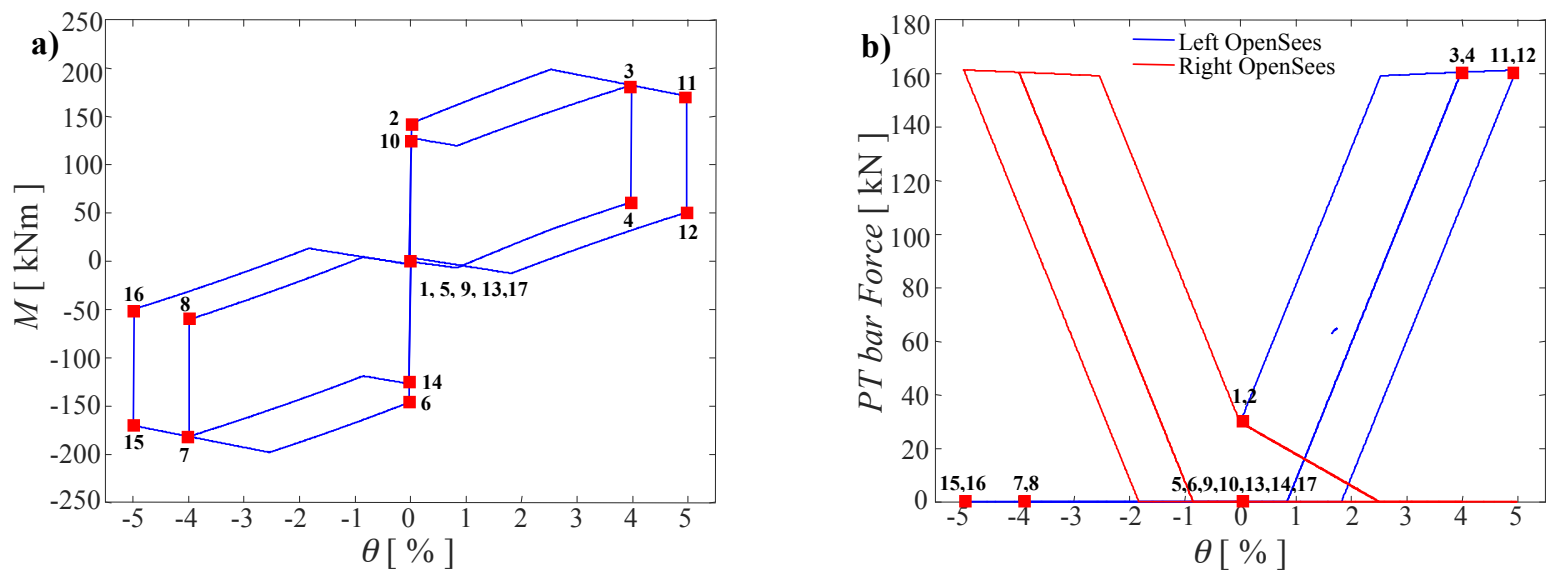

Figure 13. (a) Cyclic moment-rotation behavior of the column base from OpenSees for two loading cycles (rotations equal to 0.04 and $0.05 \mathrm{rads}$ ); (b) forces in the PT bars. Numbers associate the results in both graphs and illustrate how yielding of the PT bars affect the cyclic moment-rotation behavior.

\section{EFFECT OF ROCKING COLUMN BASE ON GLOBAL SEISMIC RESPONSE}

\subsection{Seismic design}

Figure 14 shows the plan and elevation views of a 5-story, 5-bay by 3-bay prototype steel building having two 
identical perimeter seismic-resistant frames in the $x$ plan direction. The study focuses on one perimeter seismicresistant frame. This frame is designed as a SC-MRF using PT beam-column connections with the aid of the design procedure proposed in [32]. The interior gravity frames (with pinned beam-column connections and pinned column bases) are coupled with the SC-MRF through the floor diaphragm.
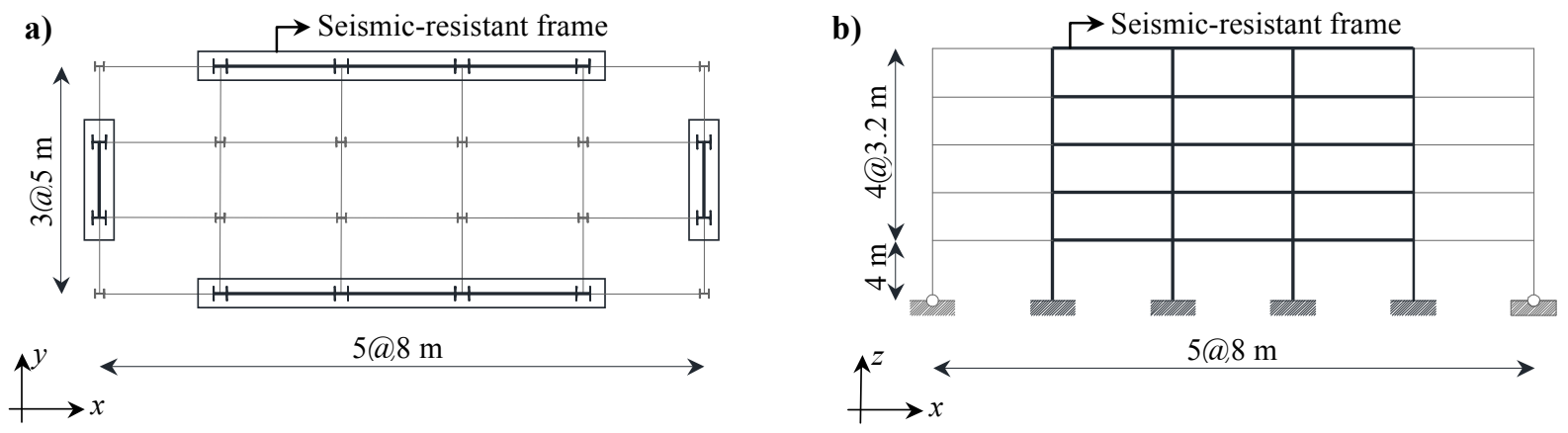

Figure 14. (a) Plan view; and (b) elevation view of the prototype building.

Table 2. Beam and column cross-sections.

\begin{tabular}{c|cc}
\hline Floor & Column & Beam \\
\hline 1 & HEB650 & IPE550 \\
2 & HEB650 & IPE600 \\
3 & HEB650 & IPE550 \\
4 & HEB600 & IPE500 \\
5 & HEB600 & IPE500 \\
\hline
\end{tabular}

The building has ductile non-structural elements, and therefore, the target interstory drift $\left(\theta_{s-m a x}\right)$ under the frequently occurred earthquake (probability of exceedance of $10 \%$ in 10yrs) is equal to $0.75 \%$ according to Eurocode 8 [1]. The design basis earthquake (DBE; probability of exceedance of $10 \%$ in $50 \mathrm{yrs}$ ) is expressed by the Type 1 elastic response spectrum of Eurocode 8 [1] with peak ground acceleration equal to $0.35 \mathrm{~g}$ and ground type B. The maximum credible earthquake (MCE) is assumed to have intensity equal to $150 \%$ the DBE intensity. The model used for the design is based on centerline dimensions without accounting for the finite panel zone dimensions. The steel yield strength is equal to $355 \mathrm{MPa}$ for the columns, $275 \mathrm{MPa}$ for beams and $900 \mathrm{MPa}$ for PT bars. The design results in the beam and column cross-sections provided in Table 2. The SC-MRF is designed with rigid full-strength conventional column bases that promote plastic hinges in the bottom end of the first story columns. For the same SC-MRF design, rocking damage-free column bases are also designed in Section 5.2.

\subsection{Design of rocking column bases}

All first story columns have a HEB650 cross-section profile, the target rotation is selected equal to $0.02 \mathrm{rads}$, and $N_{E d, G}$ is equal to $837 \mathrm{kN}$. The rocking column base is designed according to the procedure in Section 3. A circular hollow section with $457 \mathrm{~mm}$ diameter and a bottom steel plate with rounded edges of $70 \mathrm{~mm}$ radius are selected. The contact surface of the rounded steel plate with the base plate has dimension $b$ equal to $317 \mathrm{~mm}$. The anchor plate has $670 \mathrm{~mm}$ width and $50 \mathrm{~mm}$ thickness. The $b_{P T}$ distance among the PT bars is $450 \mathrm{~mm}$. The material properties are the same with those in Section 3. PT bars have $60 \mathrm{~mm}$ diameter, $2100 \mathrm{~mm}$ free length, and were designed for $\kappa$ equal to 0.151 . The initial post-tensioning force $T_{P T}$ is equal to $384.25 \mathrm{kN}$. The moment contribution of the FDs is equal to $313.56 \mathrm{kNm}$. The horizontal distance $b_{F D}$ among the centers of the FDs is $756.9 \mathrm{~mm}$, while $h_{F D}$ is equal to $315 \mathrm{~mm}$. The friction coefficient in the FDs is 0.15 . Four M20 class 10.9 are used in each FD. The slotted holes are designed in order to accommodate drifts up to 0.06rads without bolts bearing. The post-tensioning force in each of these bolts is equal to $98.7 \mathrm{kN}$.

\subsection{Models for the SC-MRFs and earthquake ground motions}

FE models for the SC-MRFs are developed in OpenSees [23]. Information on modeling SC-MRFs in OpenSees can be found in $[30,32,33]$. The model for the SC-MRF with rocking column bases is using the model described in Section 4.2. The SC-MRF with conventional column bases has $T_{1}$ equal to $0.94 \mathrm{sec}$, while the SC-MRF with the rocking column bases has $T_{l}$ equal to $0.867 \mathrm{sec}$ due to its shorter first story column flexible length. The difference in the period of vibration is due to the shorter flexible length of the first story columns of the SC-MRF with the rocking column bases. Ten earthquake ground motions (selected from the far-fault ground motions developed by the FEMA 
P694 project [34]) are used for nonlinear dynamic analyses. These earthquake ground motions are scaled to the DBE and MCE seismic intensities as shown in Figure 15. The seismic intensity is described by the spectral acceleration, $S_{\mathrm{a}}$, at $T_{l}[35]$, while the inherent damping ratio is $3 \%$.
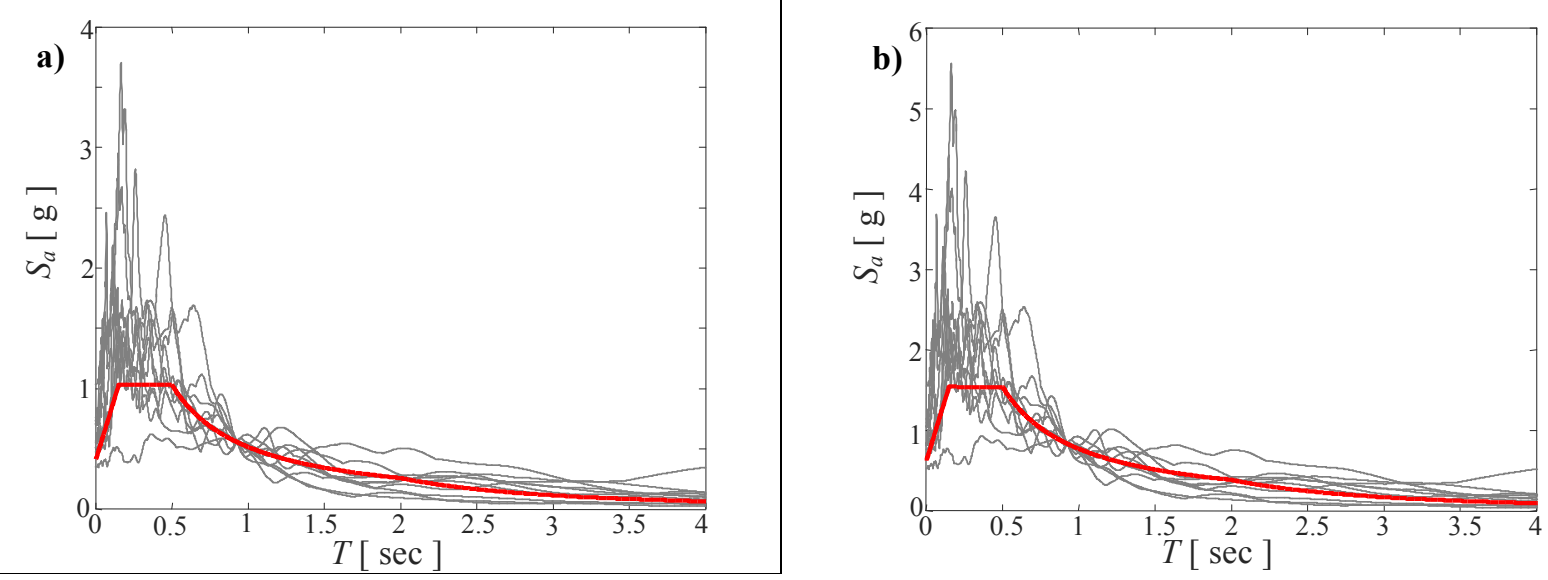

Figure 15. Scaled ground motions for the SC-MRF with rocking column bases $\left(T_{l}=0.87 \mathrm{sec}\right)$; (a) DBE and (b) MCE.

\subsection{Seismic analyses results}

Figure 16 and Figure 17 show respectively the peak interstory drifts and the residual interstory drifts of the SCMRFs with either conventional or rocking column bases for the ten earthquake ground motions. The median values are also shown with solid lines. Figure 16 shows that the use of the rocking column base results in modest increase of the peak first story drift as a consequence of the reduced rotational stiffness of the column base after rocking. It should be noted that rocking initiates for a bending moment that is smaller than the plastic moment of resistance of the first story columns. On the other hand, Figure 17 shows that the SC-MRF with conventional column bases experiences appreciable residual first story drifts due to first story column yielding. Such residual drifts reach values close to $0.5 \%$ under individual earthquake ground motions (i.e. a critical value that is considered as the limit beyond which repair of a steel building may not be economically viable [33]). On the other hand, the use of the rocking column base essentially eliminates the first story residual drift.
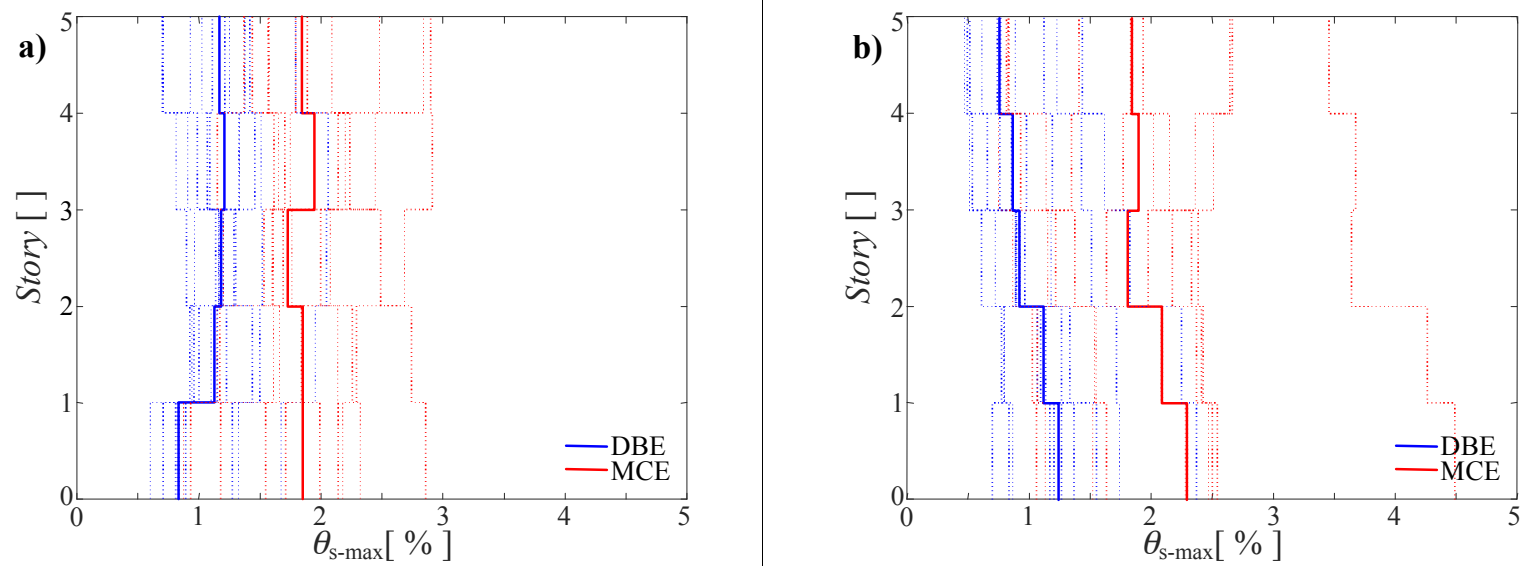

Figure 16. Peak interstory drifts from nonlinear dynamic analysis for the scaled ground motions for the DBE and MCE intensities for (a) SC-MRF (b) SC-MRF with rocking column bases. 

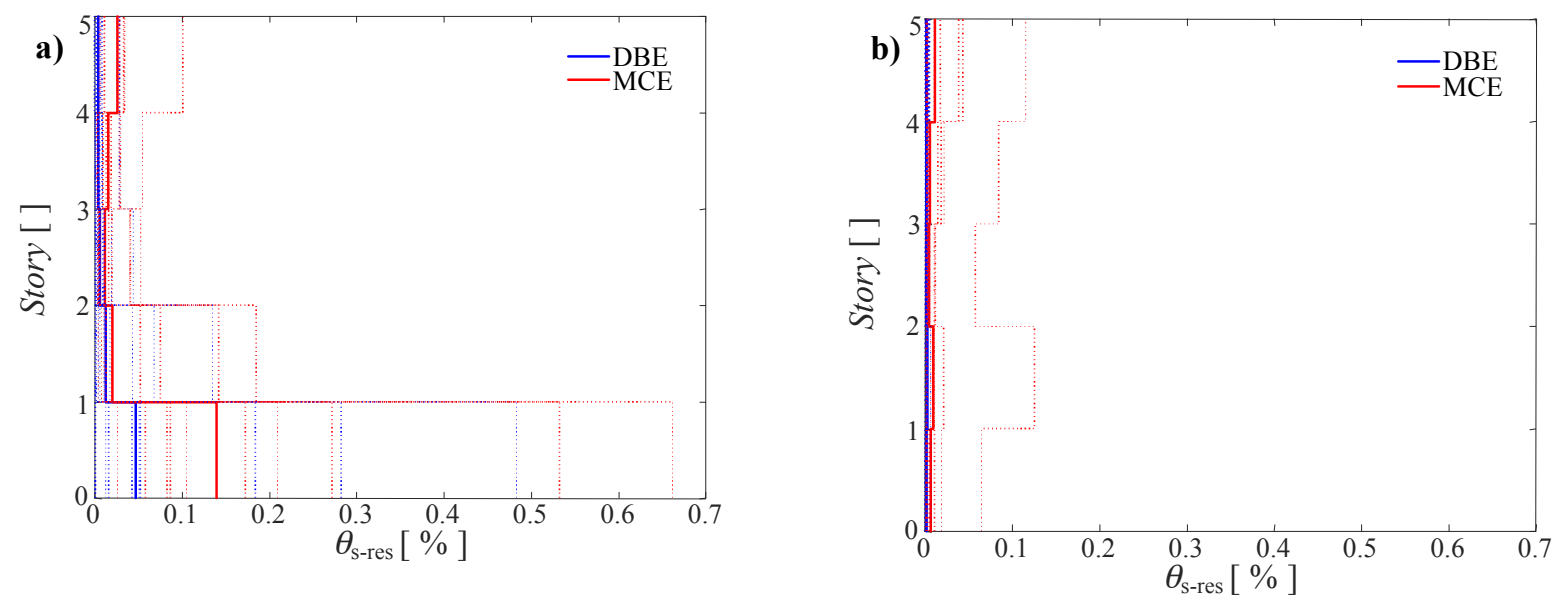

Figure 17. Residual interstory drifts from nonlinear dynamic analysis for the scaled ground motions for the DBE and MCE intensities for (a) SC-MRF (b) SC-MRF with column bases.

Figure 18 shows the first story drift time histories of the SC-MRFs for a specific earthquake ground motion scaled at the DBE and MCE intensities. This figure highlights that the two SC-MRFs experience similar peak first story drifts but the residual first story drifts are minimized for the SC-MRF with the rocking column bases. For the same earthquake ground motion, Figure 19 compares the stress-strain hysteresis in the flanges of one of the first story columns of the SC-MRFs. These figures show that the SC-MRF with conventional column bases experience plastic deformations and damage that needs to be repaired in the aftermath of strong earthquakes, while the SC-MRF with rocking column bases fully protects the columns from yielding under both the DBE and MCE.
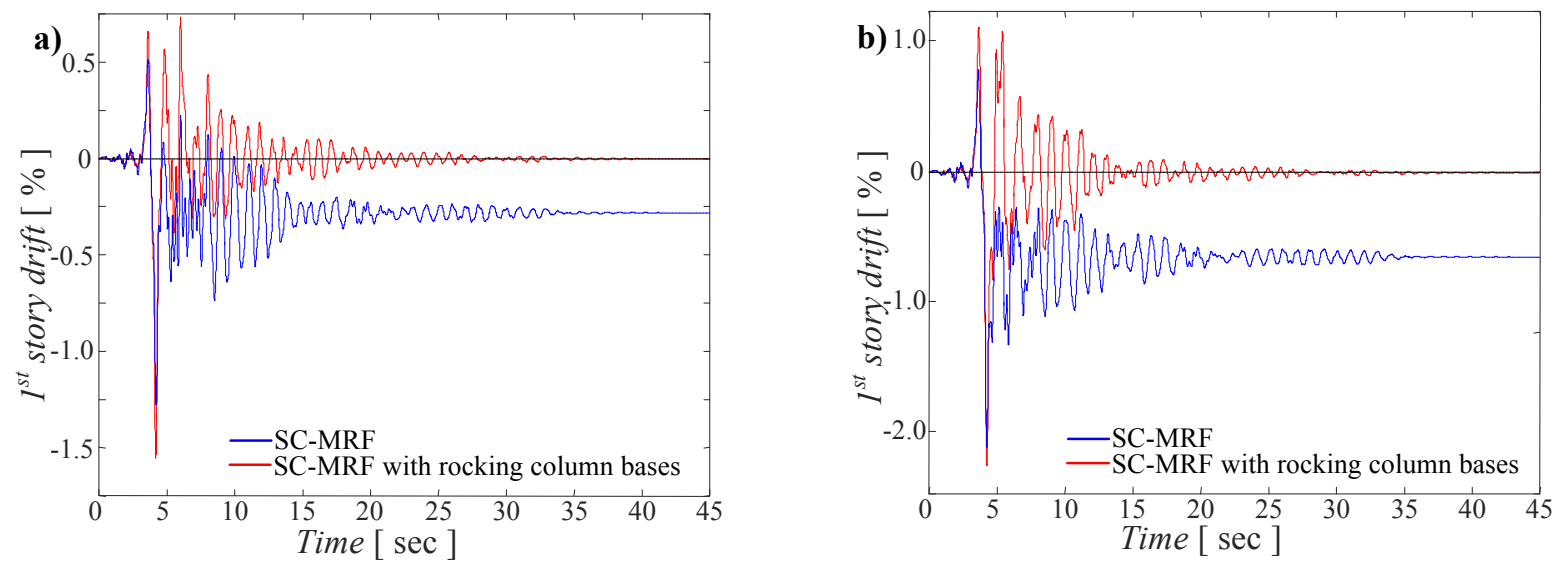

Figure 18. First story drift time histories for a specific ground motion scaled at the (a) DBE and (b) MCE intensities.
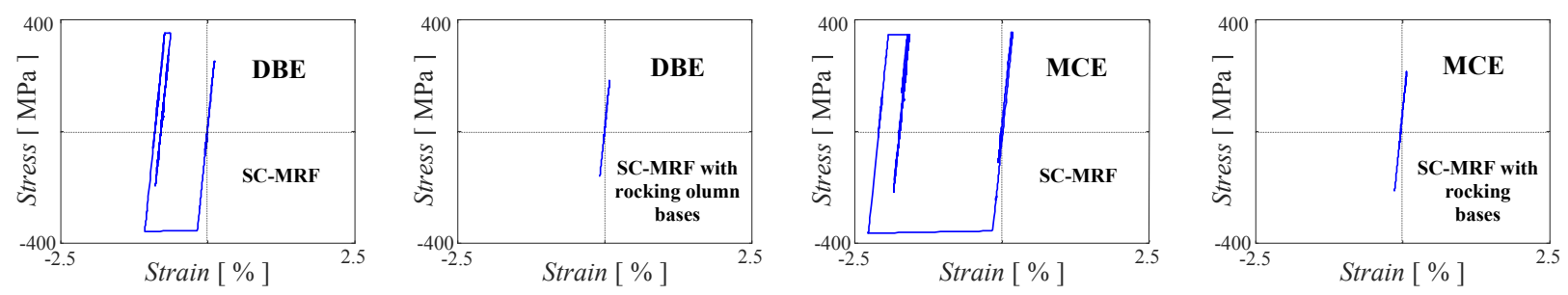

Figure 19. Stress-strain hysteresis in the flanges of one of the first story columns of the SC-MRFs for a specific ground motion scaled at the DBE and MCE intensities.

\section{CONCLUSIONS}

A rocking damage-free steel column base has been presented. The column base uses post-tensioned (PT) high strength steel bars to control rocking behavior and friction devices to dissipate seismic energy. The paper provides analytical equations that describe the monotonic and cyclic moment-rotation hysteretic curves of the column base. 
The latter consider different limit states including yielding or loss of post-tensioning in the PT bars. The column base is designed with aid of an optimum graphical design procedure, which ensures damage-free behavior, selfcentering capability, and adequate energy dissipation capacity. Both the analytical moment-rotation equations and the design procedure are validated with nonlinear finite element (FE) simulations in ABAQUS. In addition, a simplified model of the rocking column base is developed in OpenSees. This model is used to perform nonlinear dynamic analyses on steel self-centering moment-resisting frames using the rocking column base. The results show that the rocking column base fully protects the first story columns from yielding and eliminates the first story residual drift without any detrimental effect on peak interstory drifts. The study focused on the 2D rocking motion of the column base. FE models, analytical equations, and an associated design procedure that consider 3D rocking motion effects will be developed after a forthcoming experimental evaluation of the column base.

\section{APPENDIX}

The appendix provides analytical equations for the definition of the monotonic moment-rotation behavior of the column base accounting for geometrical, material and mechanical nonlinearities.

\section{A.1 Geometric nonlinearities}

Geometric nonlinearities (P- $\Delta$ effects) reduce the rotational stiffness of the column base. The moment contribution of the axial force is calculated by:

$$
M_{N}^{P \Delta}=N \cdot\left(\frac{b}{2}-H_{C} \cdot \theta\right)
$$

where $H_{C}$ is the height of the column. Moreover, the level arms of the PT bar forces are given by:

$$
z_{P T, u}^{P \Delta}=z_{P T, u}-H_{C B} \theta \quad z_{P T, d}^{P \Delta}=z_{P T, d}+H_{C B} \theta
$$

where $H_{C B}$ is defined in Figure 3(a). The change in the direction of the force of the PT bars is negligible. The moment contribution of the PT bars is given by:

$$
M_{P T}^{P \Delta}(\theta)=M_{P T, 0}+S_{P T} \theta-S_{P T}^{P \Delta, 1} \theta-S_{P T}^{P \Delta, 2} \theta^{2} \quad \text { for } \theta \leq \theta_{T}
$$

where the quantities that reflect the reduction in the rotational stiffness of the PT bars due to geometric nonlinearities are calculated by:

$$
\begin{gathered}
S_{P T}^{P \Delta, 1}=4 T_{P T} H_{C B} \\
S_{P T}^{P \Delta, 2}=2 K_{P T}\left(z_{P T, u}-z_{P T, d}\right) H_{C B}
\end{gathered}
$$

\section{A.2 Material and mechanical nonlinearities}

The rotational stiffness contribution of the PT bars in case of material nonlinearities (yielding of PT bars in position $u$ ), mechanical nonlinearities (loss of post-tensioning of PT bars in position $d$ ), or combination of material and mechanical nonlinearities (yielding of PT bars in position $u$ and loss of post-tensioning of PT bars in position $d$ ) are given by Equations (A6), (A7), and (A8), respectively:

$$
\begin{gathered}
S_{P T, y}=2 K_{P T}\left(\beta z_{P T, u}^{2}+z_{P T, d}^{2}\right) \\
S_{P T, f}=2 K_{P T} z_{P T, u}^{2} \\
S_{P T, y f}=2 \beta K_{P T} z_{P T, u}^{2}
\end{gathered}
$$

The moment contribution of the PT bars can be calculated as:

$$
\begin{gathered}
\text { Case } 1-\theta \geq \theta_{T} \text { and } \theta_{T}=\theta_{P T, u, y} \\
M_{P T}(\theta)=M_{P T, 0}+S_{P T} \theta_{P T, u, y}+S_{P T, y}\left(\theta-\theta_{P T, u, y}\right) \quad \theta<\theta_{P T, d, f} \\
M_{P T}(\theta)=M_{P T, 0}+S_{P T} \theta_{P T, u, y}+S_{P T, y}\left(\theta_{P T, d, f}-\theta_{P T, u, y}\right)+S_{P T, y f}\left(\theta-\theta_{P T, d, f}\right) \quad \theta \geq \theta_{P T, d, f}
\end{gathered}
$$

Case 2 - $\theta \geq \theta_{T}$ and $\theta_{T}=\theta_{P T, d, f}$

$$
M_{P T}(\theta)=M_{P T, 0}+S_{P T} \theta_{P T, d, f}+S_{P T, f}\left(\theta-\theta_{P T, d, f}\right) \quad \theta<\theta_{P T, u, y}
$$




$$
M_{P T}(\theta)=M_{P T, 0}+S_{P T} \theta_{P T, d, f}+S_{P T, f}\left(\theta_{P T, u, y}-\theta_{P T, d, f}\right)+S_{P T, y f}\left(\theta-\theta_{P T, u, y}\right) \quad \theta \geq \theta_{P T, u, y}
$$

\section{A.3 Material, mechanical and geometric nonlinearities}

In the case of material, mechanical, or material and mechanical nonlinearities, the stiffness reduction due to geometric nonlinearities is related to the following parameters:

$$
\begin{gathered}
S_{P P, y}^{P \Delta, 2}=2 K_{P T}\left(\beta z_{P T, u}-z_{P T, d}\right) H_{C B} \\
S_{P A, 2}^{P \Delta, 2}=2 K_{P T} z_{P T, u} H_{C B} \\
S_{P T, y f}^{P \Delta, 2}=2 \beta K_{P T} z_{P T, u} H_{C B}
\end{gathered}
$$

where $S_{P T, y}^{P \Delta, 2}$ is the stiffness reduction after yielding of PT bars in position $u$; $S_{P T, f}^{P \Delta, 2}$ is the stiffness reduction after loss of post-tensioning force of PT bars in position $d$, and $S_{P T, y f}^{P \Delta, 2}$ is the stiffness reduction after yielding and loss of post-tensioning force of PT bars in positions $u$ and $d$, respectively. Then, the moment contribution of the PT bars can be calculated as:

Case 1 - $\theta \geq \theta_{T}$ and $\theta_{T}=\theta_{P T, u, y}$

$$
\begin{gathered}
M_{P T}^{P \Delta}(\theta)=M_{P T, 0}+S_{P T} \theta_{P T, u, y}+S_{P T, y}\left(\theta-\theta_{P T, u, y}\right)+ \\
-S_{P T}^{P \Delta, 1} \theta-S_{P T}^{P \Delta, 2} \theta_{P T, u, y} \theta-S_{P T, y}^{P \Delta, 2}\left(\theta-\theta_{P T, u, y}\right) \theta \\
M_{P T}^{P \Delta}(\theta)=M_{P T, 0}+S_{P T} \theta_{P T, u, y}+S_{P T, y}\left(\theta_{P T, d, f}-\theta_{P T, u, y}\right)+S_{P T, y f}\left(\theta-\theta_{P T, d, f}\right)+ \\
-S_{P T}^{P \Delta, 1} \theta-S_{P T}^{P \Delta, 2} \theta_{P T, u, y} \theta-S_{P T, y}^{P \Delta, 2}\left(\theta_{P T, d, f}-\theta_{P T, u, y}\right) \theta-S_{P T, y f}^{P \Delta, 2}\left(\theta-\theta_{P T, d, f}\right) \theta
\end{gathered}
$$

Case 2 - $\theta \geq \theta_{T}$ and $\theta_{T}=\theta_{P T, d, f}$

$$
\begin{gathered}
M_{P T}^{P \Delta}(\theta)=M_{P T, 0}+S_{P T} \theta_{P T, d, f}+S_{P T, f}\left(\theta-\theta_{P T, d, f}\right)+\quad \theta<\theta_{P T, u, y} \\
-S_{P T}^{P \Delta, 1} \theta-S_{P T}^{P \Delta, 2} \theta_{P T, d, f} \theta-S_{P T, f}^{P \Delta, 2}\left(\theta-\theta_{P T, d, f}\right) \theta \quad \\
M_{P T}^{P \Delta}(\theta)=M_{P T, 0}+S_{P T} \theta_{P T, d, f}+S_{P T, f}\left(\theta_{P T, u, y}-\theta_{P T, d, f}\right)+S_{P T, y f}\left(\theta-\theta_{P T, u, y}\right)+ \\
-S_{P T}^{P \Delta, 1} \theta-S_{P T}^{P \Delta, 2} \theta_{P T, d, f} \theta-S_{P T, y}^{P \Delta, 2}\left(\theta_{P T, u, y}-\theta_{P T, d, f}\right) \theta-S_{P T, y f}^{P \Delta, 2}\left(\theta-\theta_{P T, u, y}\right) \theta \quad \theta \geq \theta_{P T, u, y}
\end{gathered}
$$

\section{ACKNOWLEDGEMENTS}

This research is supported by Marie Sklodowska-Curie Action Fellowships within the H2020 European Programme. Any opinions, findings, and conclusions or recommendations expressed in this paper are those of the authors and do not necessarily reflect the views of the European Commission.

\section{REFERENCES}

1. Eurocode 8. Design of structures for earthquake resistance. Part 1: General rules, seismic action and rules for buildings. European Committee for Standardization 2005, Brussels, Belgium.

2. Federal Emergency Management Agency. FEMA 350. Recommended seismic design criteria for new steel moment-frame buildings. SAC Joint Venture 2000, Washington, DC.

3. Christopoulos C, Filiatrault A. Principles of passive supplemental damping and seismic isolation. IUSS Press 2006, Pavia, Italy.

4. Symans MD, Charney FA, Whittaker AS, Constantinou MC, Kircher CA, Johnson MW, McNamara RJ. Energy dissipation systems for seismic applications: Current practice and recent developments. Journal of Structural Engineering (ASCE) 2008; 134(1): 3-21.

5. Chancellor NB, Eatherton MR, Roke DA, Akbas T. Self-centering seismic lateral force resisting systems: Highperformance structures for the city of tomorrow. Buildings 2014; 4:520-548.

6. Garlock M, Sause R, Ricles JM. Behavior and design of posttensioned steel frame systems. Journal of Structural Engineering 2007; 133(3):389-399.

7. Kim HJ, Christopoulos C. Seismic design procedure and seismic response of post-tensioned self-centering steel frames. Earthquake Engineering \& Structural Dynamics 2008; 38(3):355-376.

8. Eurocode 3. Design of steel structures - Part 1.8: Design of Joints. European Committee for Standardization 
2005, Brussels, Belgium.

9. Latour M, Rizzano G. Full strength design of column base connections accounting for random material variability. Engineering Structures 2013; 48:458-471.

10. Latour M, Rizzano G. A theoretical model for predicting the rotational capacity of steel base joints. Engineering Structures 2013; 91:89-99.

11. Rodas PT, Zareian F, Kanvinde M. Hysteretic model for exposed column-base connections. Journal of Structural Engineering (ASCE) 2016; in press (available online)

12. Grauvilardell JE, Lee D, Hajjar JF, Dexter RJ. Synthesis of design, testing and analysis research on steel column base plate connections in high-seismic zones. Report ST-04-02, 2006. Dept. of Civil Engineering, Univ. of Minnesota, USA

13. Zareian F, Kanvinde A. Effect of column-base flexibility on the seismic response and safety of steel momentresisting frames. Earthquake Spectra 2013; 29(4): 1537-1559.

14. Kanvinde AM, Grilli DA, Zareian F (2012). Rotational stiffness of exposed column base connections: experiments and analytical models. Journal of Structural Engineering (ASCE); 138(5):549-560.

15. Mackinven H, MacRae GA, Pampanin S, Clifton GC, Butterworth J. Generation four steel moment frame joints. $8^{\text {th }}$ Pacific Conference on Earthquake Engineering 2007, Singapore.

16. Clifton GC. Semi-rigid joints for moment resisting steel framed seismic resisting systems. Ph.D. Thesis 2005, Dept. of Civil and Environmental Engineering, University of Auckland, New Zealand.

17. MacRae GA, Urmson CR, Walpole WR, Moss P, Hyde K, Clifton C. Axial shortening of steel columns in buildings subjected to earthquakes. Bulletin of the New Zealand Society for Earthquake Engineering 2009; 42(4): 275-287

18. Yamanishi T, Kasai K, Takamatsu T, Tamai H. Innovative column-base details capable of tuning rigidity and strength for low to medium-rise steel structures. 15 th World Conference on Earthquake Engineering 2012 , Lisbon, Portugal.

19. Chi H, Liu J. Seismic behavior of post-tensioned column base for steel self-centering moment resisting frame. Journal of Constructional Steel Research 2012; 78: 117-130.

20. Chou C-C, Chen JH. Analytical model validation and influence of column bases for seismic responses of steel post-tensioned self-centering MRF systems. Engineering Structures 2011; 33(9): 2628-2643.

21. Borzouie J, MacRae GA, Chase JG, Rodgers GW, Clifton GC. Experimental studies on cyclic performance of column base strong axis - aligned asymmetric friction connections. Journal of Structural Engineering (ASCE) 2016; 142(1): 04015078.

22. ABAQUS/Standard and ABAQUS/Explicit - Version 6.13.1. ABAQUS Theory Manual, Dassault Systems, 2013.

23. McKenna F, Fenves GL, Scott MH. OpenSees: Open system for earthquake engineering simulation. PEER Center 2006, Berkeley, CA.

24. Kamperidis VC, Karavasilis TL, Vasdravellis G. Design and modeling of a novel damage-free steel column base. Eighth International Conference on Advances in Steel Structures. Lisbon, Portugal, July 22-24, 2015.

25. Wolski M, Ricles J, Sause R. Experimental Study of a Self-Centering Beam-Column Connection with Bottom Flange Friction Device. Journal of Structural Engineering (ASCE) 2009; 135(5): 479-488.

26. Latour M, Piluso V, Rizzano G. Free from damage beam-to-column joints: Testing and design of DST connections with friction pads. Engineering Structures 2015; 85: 219-233.

27. Eurocode 3. Design of steel structures - Part 1.1: General rules and rules for buildings. European Committee for Standardization 2005, Brussels, Belgium.

28. Coelho A, Bijlaard F, Gresnigt N, da Silva LS. Experimental assessment of the behavior of bolted T-stub connections made up of welded plates. Journal of Constructional Steel Research 2004; 60(2): $269-311$.

29. Haremza C, Santiago A, da Silva LS. Experimental behavior of heated composite steel-concrete joints subject to variable bending moments and axial forces. Engineering Structures 2013; 51: 150-161.

30. Dimopoulos AI, Karavasilis TL, Vasdravellis G, Uy B. Seismic design, modelling and assessment of selfcentering steel frames using post-tensioned connections with web hourglass shape pins. Bulletin of Earthquake Engineering 2013; 11(5): 1797-1816.

31. Piluso V., Montuori R., Troisi M. Innovative structural details in MR-frames for free from damage structures. Mechanics Research Communications 2014; 58: 146-156.

32. Tzimas AS, Dimopoulos AI, Karavasilis TL. EC8-based seismic design and assessment of self-centering posttensioned steel frames with viscous dampers. Journal of Constructional Steel Research 2015; 105: 60-73.

33. Dimopoulos AI, Tzimas AS, Karavasilis TL, Vamvatsikos. Probabilistic economic seismic loss estimation in steel buildings using post-tensioned moment-resisting frames and viscous dampers. Earthquake Engineering \& Structural Dynamics 2016; DOI: 10.1002/eqe.2722. 
34. FEMA P695. Quantification of building seismic performance factors. ATC-63 Project. Applied Technology Council: CA. USA, 2008.

35. Freddi F, Padgett JE, Dall'Asta A. Probabilistic Seismic Demand Modeling of Local Level Response Parameters of an RC Frame. Bulletin of Earthquake Engineering 2017; 15:1-23. DOI 10.1007/s10518-0169948-x. 